\title{
Complementing Optical Remote Sensing with Synthetic Aperture Radar Observations of Hail Damage Swaths to Agricultural Crops in the Central United States
}

\author{
Jordan R. Bell, ${ }^{a}$ EsAyas Gebremichael, ${ }^{\mathrm{b}}$ ANDREw L. Molthan, ${ }^{\mathrm{a}}$ LORI A. SCHUltz, \\ Franz J. MEyer, ${ }^{\mathrm{d}, \mathrm{e}}$ CHristopher R. HAin, ${ }^{\mathrm{a}}$ Suravi SHrestha, ${ }^{\mathrm{c}}$ AND K. COLE PAyne \\ ${ }^{\mathrm{a}}$ Earth Science Branch, NASA Marshall Space Flight Center, Huntsville, Alabama \\ ${ }^{\mathrm{b}}$ Department of Geological Sciences, Texas Christian University, Fort Worth, Texas \\ ${ }^{\mathrm{c}}$ Earth System Science Center, University of Alabama in Huntsville, Huntsville, Alabama \\ d Alaska Satellite Facility, University of Alaska Fairbanks, Fairbanks, Alaska \\ ${ }^{\mathrm{e}}$ Geophysical Institute, University of Alaska Fairbanks, Fairbanks, Alaska
}

(Manuscript received 23 May 2019, in final form 13 February 2020)

\begin{abstract}
The normalized difference vegetation index (NDVI) has been frequently used to map hail damage to vegetation, especially in agricultural areas, but observations can be blocked by cloud cover during the growing season. Here, the European Space Agency's Sentinel-1A/1B C-band synthetic aperture radar (SAR) imagery in co- and cross polarization is used to identify changes in backscatter of corn and soybeans damaged by hail during intense thunderstorm events in the early and late growing season. Following a June event, haildamaged areas produced a lower mean backscatter when compared with surrounding, unaffected pixels [vertical-vertical (VV): $-1.1 \mathrm{~dB}$; vertical-horizontal (VH): $-1.5 \mathrm{~dB}$ ]. Later, another event in August produced an increase in co- and cross-polarized backscatter (VV: $0.7 \mathrm{~dB} ; \mathrm{VH}: 1.7 \mathrm{~dB}$ ) that is hypothesized to result from the combined effects of crop growth, change in structure of damaged crops, and soil moisture conditions. Hail damage regions inferred from changes in backscatter were further assessed through coherence change detections to support changes in the structure of crops damaged within the hail swath. While studies using NDVI have routinely concluded a decrease in NDVI is associated with damage, the cause of change with respect to the damaged areas in SAR backscatter values is more complex. Influences of environmental variables, such as vegetation structure, vegetation maturity, and soil moisture conditions, need to be considered when interpreting SAR backscatter and will vary throughout the growing season.
\end{abstract}

\section{Introduction}

The use of satellite remote sensing in mapping of crop type, health, and phenology has evolved to include a variety of applications in agricultural assessment including crop classification (Viña et al. 2004; Wardlow et al. 2007; Howard et al. 2012; Bargiel 2017; Kussul et al. 2017), crop condition (Zhang et al. 2014), and precision agriculture (Reigber et al. 2013). Agriculture is particularly susceptible to the impacts of weather, including frost, drought, flood, and other meteorological hazards.

In the central United States, the primary growing season coincides with severe thunderstorms that occur frequently in the spring and summer months. Vegetation affected by damaging wind and/or large hail is often unrecoverable or damaged to the point where it will lag

Corresponding author: Jordan R. Bell, jordan.r.bell@nasa.gov behind in growth and greenness relative to the surrounding nondamaged areas, leading to large swaths of damage during the growing season. Changnon (1977) examined several years of NOAA/NWS datasets, local mesonetworks, and insurance claims throughout the Midwest to characterize hail damage swaths. The study found hail damage swaths on average ranged in lengths from 80 to $330 \mathrm{~km}$ and widths from 10 to $25 \mathrm{~km}$. By the late 2000s, hail damage to agricultural crops averaged $\$ 580$ million annually (Changnon et al. 2009). Because of the large areal extent of these hail damage swaths and isolated public storm reports of hail size in rural areas, comprehensive ground surveys can be very time-consuming, costly, and incomplete (Bentley et al. 2002). Although detailed damage assessments are routinely performed for highimpact wind and tornado events by the NWS, they are not often performed for hail damage.

An ever-growing public and private-sector constellation of satellite remote sensors has led to an increased 
use of remote sensing data in mapping hail damage swaths of large spatial extent. For example, Klimowski et al. (1998) mapped a hail damage swath across South Dakota using the GOES-8 visible band, with a track that measured $120 \mathrm{~km}$ long and $7-11 \mathrm{~km}$ wide. The increased prevalence of near-infrared imaging permitted hail damage mapping using normalized difference vegetation index (NDVI) (Rouse et al. 1974; Tucker 1979) to identify areas of damaged vegetation. NDVI values range from -1 to 1 , where values closer to 1 indicate greener and healthier vegetation, values closer to 0 typically represent little to no green vegetation, and negative values often correspond to cloud contamination or water.

Bentley et al. (2002) utilized pre- and poststorm NDVI derived from the Landsat-7 Enhanced Thematic Mapper Plus (ETM+) to correlate decreased NDVI in Illinois to Storm Data ground reports to improve mapping of damage for the weather community and insurance sector. Parker et al. (2005) mapped hail damage in South Dakota using rolling 7-day maximum NDVI composites, documented changes in surface temperature and moisture within the damage scar region, and captured mesoscale impacts of these land surface differences on convective development through numerical modeling. Gallo et al. (2012) compared pre- and postevent, 7-day NDVI composites to map a hail damage scar in northern Iowa and compared NDVI change to storm reports of hail size and radar-estimated hail size. Molthan et al. (2014) examined hail damage scars from a 2011 thunderstorm event by differencing cloud-free values against a 20-day moving NDVI maximum and radar-based estimates of maximum hail size. Bell and Molthan (2016) focused on single-day NDVI and land surface temperature maps, using kernel filters to difference pixels against their immediate background, and identified damage areas through thresholding approaches.

Applications of NDVI are blocked by cloud cover and limited to periods with solar illumination. To fill these gaps, synthetic aperture radar (SAR) remote sensing acquires images of the surface regardless of illumination and with minimal impacts from nonprecipitating cloud cover at wavelengths common in public and commercially available datasets (Bouaraba et al. 2012; Casey et al. 2016). SAR measures the amplitude (intensity) and phase information as part of the backscattered electromagnetic radiation returned to the sensor by the imaged surface. After sensor calibration, the strength of the backscattered signal is expressed as the backscatter coefficient ( $\sigma^{0}$, usually in decibels) and varies depending on the physical and electrical properties of the imaged surface (Laur et al. 2004; Moreira et al. 2013). SAR backscatter return signals of crop fields or vegetation depend upon a number of factors including sensor wavelength and polarization, and surface characteristics such as canopy structure (size, shape, and orientation of plant tissue), surface roughness, dielectric properties (soil type and moisture), and canopy water content (McNairn et al. 2009; Cable et al. 2014; Forkuor et al. 2014; Canisius et al. 2018). Depending on the wavelength of the sensor, the backscatter from dry soil targets represents the result of the interaction between the radar signal and features at shallow depth. In the case of wet soils, the presence of water restricts the subsurface imaging and the backscatter portrays signal-target interaction on the surface (Scott et al. 2017). The incidence angle also contributes to the variation of backscatter intensity. Small incidence angles have higher penetration capability into vegetation canopy compared with larger incidence angles (Larrañaga and Álvarez-Mozos 2016).

During the early growth stages of crops such as corn and soybean, the backscatter retrieved from a given field represents the cumulative sum of contributions from both the vegetation canopy and the underlying soil. Types of scattering mechanisms common in vegetation analysis include single-bounce scattering of the radar signal off of the top of the vegetation surface, doublebounce scattering in the case of growing vegetation surrounded by water, and more complex scenarios such as an increase in backscatter due to volume scattering from crop features such as the vegetative canopy (Freeman and Durden 1998; White et al. 2015). The backscatter from distributed targets is usually a combination of scattering from different sources, but a single scattering mechanism is usually dominant (Jiao et al. 2011). Backscatter coefficient for an imaged surface is highly influenced by the polarization of the emitted and received SAR signal and its interaction with the detected objects, permitting the identification of damaged or partially damaged crop fields and detection of water beneath the crop canopy (Haldar et al. 2012). The copolarization [horizontal-horizontal (HH) or vertical-vertical (VV)] and cross-polarization [horizontalvertical (HV) or vertical-horizontal (VH)] components of emitted and received signals provide greater insight into backscattering mechanisms and material sampled at the surface. Cross-polarized backscatter is sensitive to crop structure within the total canopy volume and preferred for identifying vegetation and crops, or for capturing variations within different crop types due to the volumetric scattering of the depolarized SAR signal from the dense canopy (Karjalainen et al. 2008; Li and Wang 2018). Moreover, several studies have shown that cross polarizations are sensitive to crop growth stages (Jiao et al. 2011; Liu et al. 2013; Wiseman et al. 2014). In the early stages of the plant growth, surface scattering from the interaction of the radar signal with the sparse canopy, stem, and the soil surface dominates the backscatter 
return signal, and hence copolarized images tend to be brighter and show high mean backscatter values when compared with the cross-polarized images (Haldar et al. 2012; Cable et al. 2014). McNairn et al. (2014) stipulated that an increase in biomass will increase the backscatter value retrieved from crop fields and vice versa. Contribution of the soil surface to the overall backscatter return declines, especially in the case of shortwavelength SAR sensors, with the growth and development of canopy (Jiao et al. 2011; Cable et al. 2014).

SAR imaging capabilities and ties to physical changes in both plant structure and material imply an ability to map the effects of severe weather on agricultural crops and vegetation. European Space Agency (ESA) Sentinel-1 SAR remote sensing ( $C$ band) measures radar backscatter of the intercepted vegetation, where reductions in backscatter are expected for crops susceptible to severe weather hazards due to the loss of physical material returning a backscattered signal. Changes over time are commonly monitored through comparison of two or more multitemporal scenes with common acquisition mode and viewing geometry (Scheuchl et al. 2009) including amplitude change detection (ACD) and coherent change detection (CCD) methods (Sanyal and Lu 2004; Al-sharif et al. 2013). ACD methods are based on observations and analyses of the temporal changes in the mean backscatter coefficient of a target based on an image pair. Plank (2014) recommends three or more multitemporal SAR images be used to fully assess the damage/disaster and other surface changes. In the case of agricultural crops with structure that evolves over time, analysis of the long-term temporal changes of the backscatter coefficient (time series) is better suited to capture and observe the evolution and different stages of the crop growth cycle in contrast to a single ACD product derived from two images (Nguyen et al. 2016; Song and Wang 2019). CCD uses the phase information retrieved from two single-look complex (SLC) images to measure the degree of statistical similarity of the phase information of the pixels before and after an event (Preiss and Stacy 2006). Coherence values range from 0 to 1 ; surfaces that have undergone significant change exhibit coherence values close to 0 , and coherence values close to 1 signify that no surface change has occurred between the satellite revisit times (Malinverni et al. 2014).

Time series of radar backscatter measurements, ACD, and CCD methods can be used in combination to document changes in vegetation cover. In agricultural fields, amplitude and coherence changes may be caused by growth of plant material, changes in the orientation of vegetation due to growth and wind effects, and the amount or dielectric properties of exposed soil, while coherence also depends further upon temporal resolution, spatial baseline, and accuracy of the coregistration of the paired SAR images (Wegmuller 1999).

Few studies have used SAR data to explore impacts of severe weather on overall crop and vegetation structure or changes on the growth cycle. Kenduiywo et al. (2018) applied multitemporal crop classification procedures on Sentinel-1 images to capture crop phenologies. Wheat felled by strong winds confounded classification as the wind altered the wheat structure and resulted in a backscatter value that resembled rye. Similarly, Zhao et al. (2017) studied influences of strong winds on the condition and yield of wheat and canola crops using polarimetric analysis of C-band $R A D A R S A T-2$ data. They noted an increase in the VV and VH, and a decrease on the $\mathrm{HH}$ polarimetric backscatter response in the damaged crops, and they attributed this variation to changes to the vertical structure of the crops and variations in crop moisture levels.

In this study, we examine polarimetric properties and coherence pairs to identify severe weather damage to agriculture for two case studies in the central United States (Fig. 1). Case study 1, located in South Dakota and Minnesota, resulted from supercell thunderstorms that produced damaging winds and large hail on 21 June 2017. Case study 2, in Nebraska, resulted from a similar storm type that occurred on 6 August 2018. Crop damage caused by each event were visibly evident as scarring in various true-color and NDVI imagery. These cases are examined to answer the following questions:

1) How do visual and quantitative methods from optical remote sensing (e.g., NDVI) compare to SAR amplitude and coherence information for these events?

2) How do SAR signatures evolve over time, relative to their signatures in optical remote sensing?

The pursuit of these questions is motivated by the growing constellation of public and private-sector SAR remote sensing and future opportunities to apply SAR to damage assessment in regions such as the central United States where these events are frequent.

\section{Data}

\section{a. NASA Terra and Aqua MODIS}

Daily surface reflectance data acquired by the Moderate Resolution Imaging Spectroradiometer (MODIS) instruments aboard the NASA Terra and Aqua satellites were used to create NDVI products and true-color composites for this study. Level-2 Terra (MOD09GQ; Vermote and Wolfe 2015a) and Aqua (MYD09GQ; Vermote and Wolfe 2015b) 250-m-resolution MODIS products were obtained from the NASA Land Processes Distributed Active 


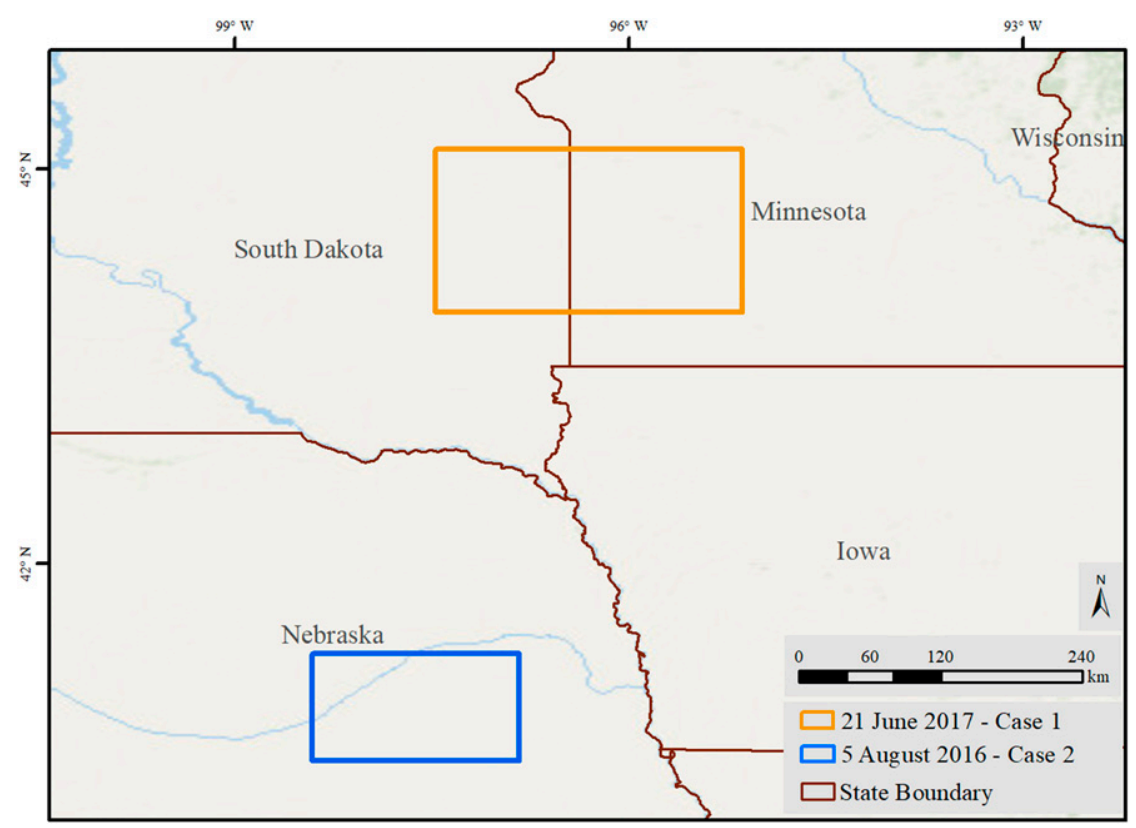

FIG. 1. Coverage areas of the two case studies that are presented in this study.

Archive Center (LP-DAAC; https://lpdaac.usgs.gov). Level-2 products are atmospherically corrected for gaseous and aerosol scattering and absorption, cirrus contamination, and atmosphere coupling effects. Red $(0.645 \mu \mathrm{m})$ and near-infrared $(0.865 \mu \mathrm{m})$ channels at their native $250-\mathrm{m}$ spatial resolution were used to create a single-day NDVI for quantitative comparisons of damaged and undamaged background areas. In cases where grid cells were sampled by two overpasses, products include the nearest-nadir and clearest cloud conditions (Vermote and Wolfe 2015a, 2015b). Products with all visible and near-infrared bands at 500-m spatial resolution (MOD09GA; Vermote and Wolfe 2015c; MYD09GA; Vermote and Wolfe 2015d) were used to create true- and false-color single-day composites. The composites were used for qualitative visual damage identification and in creating manual surveys of the identified damaged areas. The MODIS Reprojection Toolkit ${ }^{1}$ was used to stitch neighboring sinusoidal grid tiles to create a domain over the central United States.

\section{b. ESA Sentinel-1A/B synthetic aperture radar}

Sentinel-1 is an ESA mission that is made up of two polar-orbiting satellites (Sentinel-1A/1B) each equipped with a C-band SAR $(5.6 \mathrm{~cm}$; Nagler et al. 2015). This

\footnotetext{
${ }^{1}$ The MODIS Reprojection Toolkit was deprecated in early 2019; the new tool Hierarchical Data Format for the Earth Observing System (HDF-EOS) to GeoTIFF (HEG), is available online (https:// newsroom.gsfc.nasa.gov/sdptoolkit/HEG/HEGHome.html).
}

study utilized data originally provided by ESA but acquired from the Alaska Satellite Facility (ASF) DAAC after further processing through the Hybrid Pluggable Processing Pipeline (HyP3; Hogenson et al. 2016). HyP3 is a cloud-based SAR data processing infrastructure developed at ASF used to produce multiple products for analysis and interpretation. Here, HyP3 provided radiometrically terrain corrected (RTC) imagery for analysis. RTCs are derived from Level-1 Ground Range Detected (GRD) products, which are multilook SAR data projected to ground range using an Earth ellipsoid model (Rajah et al. 2018). RTCs mitigate the geometric and radiometric distortions inherited to the side-looking geometry of the SAR imagery (Shimada 2010). The RTCs were created using the GAMMA software package (Werner et al. 2000) and a 30-m DEM from the National Elevation Dataset ${ }^{2}$ (USGS 2017) for SAR geometric correction while radiometric corrections were applied using the pixel-area integration approach (Small 2011; Hogenson et al. 2016). A $7 \times 7$ enhanced Lee filter was used to despeckle the image and reduce noise. The final RTC product from HyP3 is distributed in power units that we converted to amplitude for statistical analysis and to decibels for image display (Laur et al. 2004). For the SAR backscatter time series assessments, a total of 17 co- and cross-polarization (VV and VH) RTC images were created.

\footnotetext{
${ }^{2}$ Now the 3D Elevation Program.
} 
The second product generated using $\mathrm{HyP} 3$ is used for $\mathrm{CCD}$ analyses. The coherence products were generated from three interferometric-wide-mode Level-1 SLC images. Two sets of coherence products were produced: the first pair is pre-event coherence generated from two SLC images, and the second pair is coherence from pre- and posthail imagery. Both products (RTCs and coherence pairs) utilized imagery from Sentinel-1 that were of the same incidence angle, relative orbit, and ascending flight directions.

\section{c. $M E S H$}

Confirmation of hail-affected regions was performed through the use of public storm reports via the NOAA/NWS Storm Prediction Center (SPC) and Storm Data publication and complemented by radar-based estimates of maximum hail size and potential fall region. The Maximum Expected Size of Hail (MESH) product, generated as an output of the Warning Decision Support System-Integrated Information (WDSS-II; Lakshmanan et al. 2007) system and composited into a $0.01^{\circ}$ by $0.01^{\circ}$ spatial resolution was used to estimate potential hail size and fall regions. MESH is derived from the NOAA/NWS radar network and is based upon the National Severe Storms Laboratory (NSSL) hail detection algorithm (Witt et al. 1998; Stumpf et al. 2004); it is defined as the diameter of hailstones that were larger than $75 \%$ of the observed hail size in a given storm. While MESH is noted to have a wide range of measured hail sizes within certain estimated values (Ortega et al. 2009) and may also differ in the specific location of hail measured aloft versus what is reported at the surface (Gallo et al. 2012; Molthan et al. 2013), MESH provides a spatially uniform estimate of potential maximum hail size. MESH confirms likely areas of hail impact and complements isolated, infrequent public reports of severe weather. Thunderstorms produce multiple hazards, and hail is often accompanied by strong to severe winds that can compound damage to susceptible crops. The MESH data used in this study were the $1440 \mathrm{~min}(24 \mathrm{~h})$ product that was issued daily at 1200 UTC. This was done so the MESH product would match the with the same previous 24-h storm reports from SPC. The MESH data for this study were delivered via NOAAPort, a data feed to deliver NWS products to end users and stakeholder.

\section{d. $C D L$}

The Cropland Data Layer (CDL; Boryan et al. 2011) is a geospatial product hosted under the U.S. Department of Agriculture (USDA) CropScape platform (National Agricultural Statistics Service 2019). CDL provides a crop type mask, planting frequency, water, roads, and other ancillary information. The CDL is available annually from 1997 to 2018 through supervised land-cover classification from moderate-resolution $(\sim 30 \mathrm{~m})$ satellite imagery [Landsat-8, the Disaster Monitoring Constellation (DMC) Deimos-1 and UK-DMC 2, ResourceSat-2 LISS-3, and Sentinel-2] and extensive ground-truth data. CDL is considered to be a good proxy of ground-truth validation because it provides pixel-level accuracy of $\sim 95 \%$ for major crops in intensively farmed regions (Torbick et al. 2018). Here, CDL is used to separate hail-affected and background pixels by likely crop type for the growing season in order to ascertain whether differences in NDVI and SAR occur relative to the two most prominent crop types in the study area: corn and soybeans.

\section{Method}

Potential case studies for hail-affected crops were determined through visual analysis of NASA MODIS imagery (e.g., NASA Worldview), SPC public storm reports, MESH values, and media reports. Two cases were chosen for their consistent 12-day repeat cycle of available SAR imagery for all or part of the hail damage swath and available MODIS NDVI imagery to sample and monitor the growing season through representative growing conditions.

To compare NDVI and SAR measurements between hail-affected regions and the immediate background, this study adopted the method from Bell and Molthan (2016). Using the Level-2 Terra and Aqua MODIS products (section $2 \mathrm{a}$ ), true-color, color infrared, and natural color composites were generated daily for up to 15 days postevent to identify ideal viewing conditions and best contrast between further browning of damaged vegetation and the surroundings. Images were brought into a desktop geographic information systems (GIS) application in which suspected areas of damage were defined in a shapefile as a damage polygon. Daily composites of Multi-Radar/Multi-Sensor System (MRMS) MESH (https://www.nssl.noaa.gov/projects/mrms/) for the day of the severe weather event were used to constrain (MESH $>0.00 \mathrm{~cm}$ ) the analysis within regions of likely hail fall. Positive MESH values were used as a constraint to ensure that suspected swath observed in the MODIS color composites was orientated correctly with respect to the MESH swath. Two buffers were applied to the resulting damage polygon. First, a 5-km buffer around the damage polygon captures some uncertainty between MESH and hail observations at the ground, and from past experience suggesting that visual interpretation of MODIS imagery may not capture the full length and width of damaged vegetation (Molthan et al. 2014). An additional 5-km buffer was applied to the first, resulting in a $5-10-\mathrm{km}$ distance following 

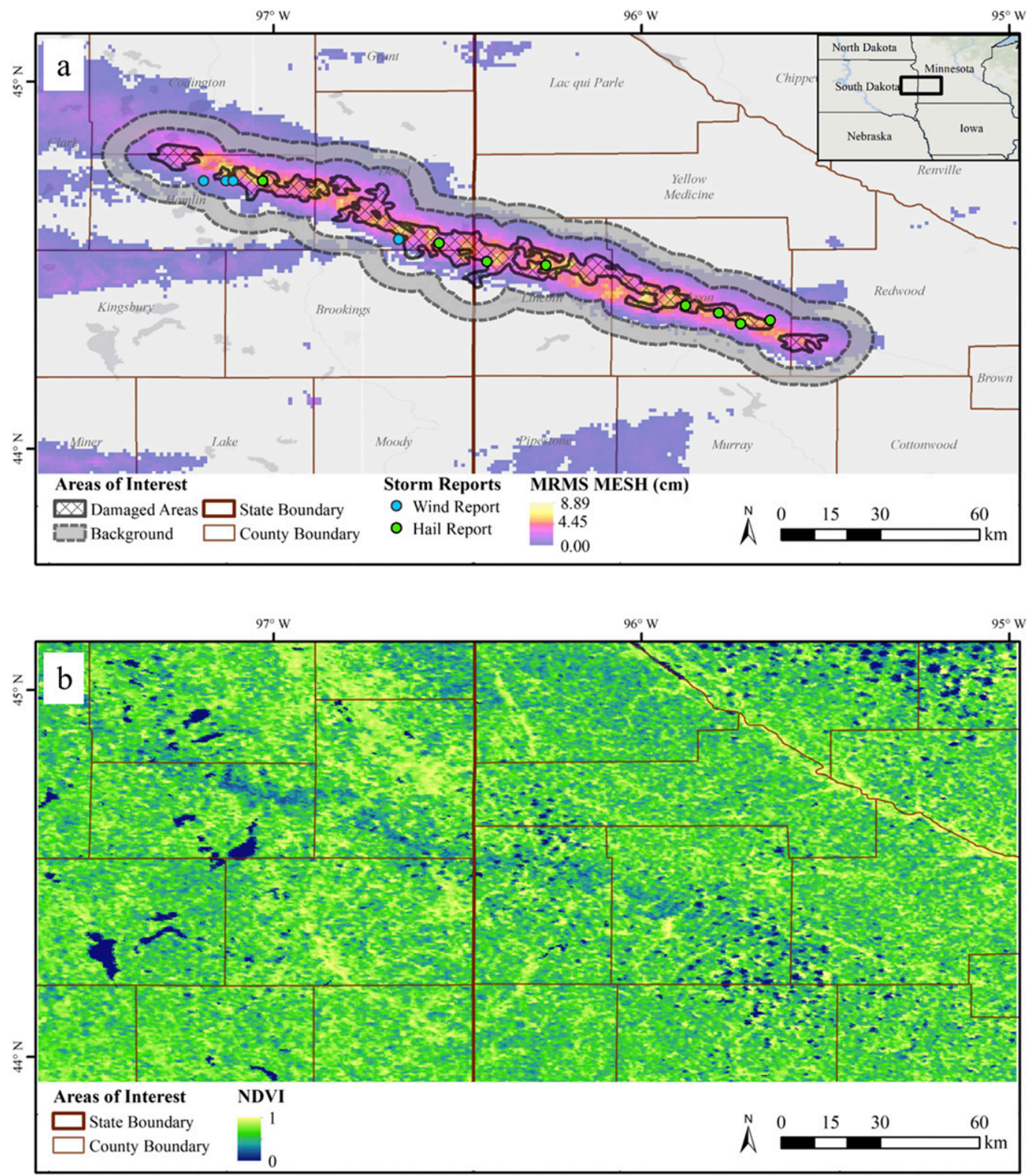

FIG. 2. (a) Diagram to visually represent how the damaged areas (hatched) were separated from the background (gray) area. The hollow space between the two areas is the 5-km buffer. An example of the MRMS 24-h MESH (from $\sim 1200$ UTC 21 Jun to 1200 UTC 22 Jun 2017) product is given by the colored shades under the damaged and background buffers. (b) Single-day NDVI for 26 Jun 2017.

the damage polygon, referred to as the unaffected background (Fig. 2a).

Single-day NDVI imagery $(250 \mathrm{~m})$ is used for comparisons between hail-affected and undamaged background regions, similar to past studies where NDVI change over multiple days, or within a single scene have been related to the degree of hail damage (Bell and Molthan 2016; Gallo et al. 2019). Analysis of NDVI metrics is limited to pixels with values of 0.20 or greater to focus on vegetated pixels, filter small clouds and shadows missed by the quality assurance (QA) mask, and remove missed urban or open water pixels. For Sentinel-1 SAR imagery, preand posthailstorm acquisitions are compared qualitatively and quantitatively using $\mathrm{VV}$ and $\mathrm{VH}$ polarized images. Similar to the NDVI products assessment, temporal changes in $\mathrm{VV}$ and $\mathrm{VH}$ backscatter are generated by comparing differences between hail-affected and background pixels as time series plots.

Time series of the mean and standard deviation and tests for statistical significance between the damage 
TABLE 1. Mean NDVI values, standard deviations (std), $z$ score, and $p$ values for both the damaged (dmg) and undamaged background (bkg) areas of the corn and soybean crops for the 21 Jun 2017 South Dakota and Minnesota case study.

\begin{tabular}{|c|c|c|c|c|c|c|c|c|c|c|c|c|}
\hline \multirow{2}{*}{$\begin{array}{c}\text { MODIS } \\
\text { date }\end{array}$} & \multicolumn{6}{|c|}{ Corn CDL areas } & \multicolumn{6}{|c|}{ Soybean CDL areas } \\
\hline & Dmg mean & Dmg std & Bkg mean & Bkg std & $z$ score & $p$ value & Dmg mean & Dmg std & Bkg mean & Bkg std & $z$ score & $p$ value \\
\hline $1 \mathrm{Jun}$ & 0.40 & 0.10 & 0.41 & 0.11 & -0.12 & 0.45 & 0.40 & 0.10 & 0.40 & 0.11 & -0.03 & 0.49 \\
\hline 5 Jun & 0.37 & 0.09 & 0.39 & 0.11 & -0.14 & 0.45 & 0.37 & 0.10 & 0.38 & 0.11 & -0.06 & 0.48 \\
\hline 14 Jun & 0.50 & 0.09 & 0.53 & 0.10 & -0.31 & 0.38 & 0.46 & 0.11 & 0.47 & 0.11 & -0.13 & 0.45 \\
\hline 20 Jun & 0.49 & 0.10 & 0.53 & 0.10 & -0.36 & 0.36 & 0.44 & 0.11 & 0.45 & 0.11 & -0.12 & 0.45 \\
\hline 26 Jun & 0.48 & 0.10 & 0.62 & 0.11 & -1.32 & 0.09 & 0.43 & 0.10 & 0.54 & 0.11 & -1.01 & 0.16 \\
\hline $2 \mathrm{Jul}$ & 0.46 & 0.12 & 0.69 & 0.10 & -2.26 & 0.01 & 0.40 & 0.10 & 0.54 & 0.11 & -1.31 & 0.10 \\
\hline $8 \mathrm{Jul}$ & 0.53 & 0.14 & 0.76 & 0.10 & -2.23 & 0.01 & 0.43 & 0.12 & 0.60 & 0.11 & -1.48 & 0.07 \\
\hline $16 \mathrm{Jul}$ & 0.66 & 0.14 & 0.82 & 0.07 & -2.17 & 0.01 & 0.55 & 0.13 & 0.74 & 0.09 & -2.01 & 0.02 \\
\hline $26 \mathrm{Jul}$ & 0.79 & 0.10 & 0.85 & 0.11 & -0.56 & 0.29 & 0.74 & 0.11 & 0.83 & 0.12 & -0.79 & 0.22 \\
\hline 4 Aug & 0.80 & 0.10 & 0.85 & 0.08 & -0.57 & 0.29 & 0.77 & 0.11 & 0.85 & 0.09 & -0.78 & 0.22 \\
\hline 19 Aug & 0.85 & 0.05 & 0.88 & 0.04 & -0.63 & 0.26 & 0.85 & 0.05 & 0.88 & 0.04 & -0.66 & 0.25 \\
\hline 30 Aug & 0.83 & 0.07 & 0.86 & 0.05 & -0.58 & 0.28 & 0.85 & 0.07 & 0.88 & 0.06 & -0.43 & 0.33 \\
\hline
\end{tabular}

region and background are provided for both NDVI and SAR parameters in addition to qualitative interpretation. Mean and standard deviations for the background regions for each crop type represent typical conditions, and $10 \%$ of the damaged region was randomly sampled to compare the hail-affected values to the undamaged background. Visual inspection of histograms for background region values and application of the central limit theorem implied Gaussian-like distributions of NDVI and backscatter values. The $z$ score,

$$
z=\frac{\bar{x}-\mu}{\sigma}
$$

where $\bar{x}$ is the $10 \%$ randomly sampled mean from the damaged areas and $\mu$ and $\sigma$ are the background mean and standard deviation, was calculated for points sampled in the damaged area using the background mean and standard deviation for comparison. From the $z$ score, a corresponding $p$ value was reported, and a threshold of 0.05 was used to note significance. Null hypotheses assume that the mean of the damaged and background regions is equal, against an alternative hypothesis that NDVI in the damaged region is less than the background, and that SAR backscatter decreases (case study 1) or increases (case study 2).

Coherence products further diagnose amplitude-based anomalies for hail-affected crops. The prehail coherence product is used to document lower-coherence pixels in the postevent pair attributable to the hail event. We applied the CCD method for hail crop impact assessment to only the south-central Nebraska case study. Since the South Dakota/Minnesota hailstorm occurred early in the season, the surface conditions (early growth, rapid structural change, reduction in soil exposure, limited canopy, etc.) produced a loss of coherence in both the hail-affected and background regions that limited the reliability of the CCD method in this case study.

\section{Results and discussion}

\section{a. 22 June 2017-South Dakota/Minnesota}

Damaging winds of $26 \mathrm{~m} \mathrm{~s}^{-1}\left(60 \mathrm{mi} \mathrm{h}^{-1}\right)$ and hail sizes up to $5.08 \mathrm{~cm}$ ( 2 in.) were reported (SPC), and a $7.24-\mathrm{cm}$ (2.85 in.) maximum MESH value was observed with severe storms during the early morning hours of 22 June 2017 that left a hail damage swath across South Dakota and Minnesota (Fig. 2a). Mostly clear skies on 26 June 2017 allowed MODIS NDVI to observe the resulting hail damage swath measuring in length of $\sim 150 \mathrm{~km}$ and width ranging from 2 to $6 \mathrm{~km}$ (Fig. 2b). The swath continued to appear prominently in NDVI imagery through July as the background areas continued with their normal growth, maturation, and greening-up while the damaged areas lagged behind in greenness and overall health (Fig. 2, Table 1).

The damaged and background areas of the corn and soybean crops exhibit increasing trends in their mean NDVI values through the 20 June 2017 MODIS acquisition (Figs. 3a,b and Table 1). The mean NDVI for corn and soybeans werer 0.51 and 0.44 , respectively, with similar standard deviations around 0.1 (Table 1). Mean values for corn and soybeans at this stage of the growing season are similar to those reported by Wardlow and Egbert (2008). A difference in the mean NDVI values of the two crops was observed in the 26 June 2017 MODIS acquisition, the first cloud-free acquisition after the 21 June damaging hail event. The damaged corn and soybean crops respectively had mean NDVI differences of 0.14 and 0.11 less than the undamaged background areas. The initial differences were not statistically 
Corn
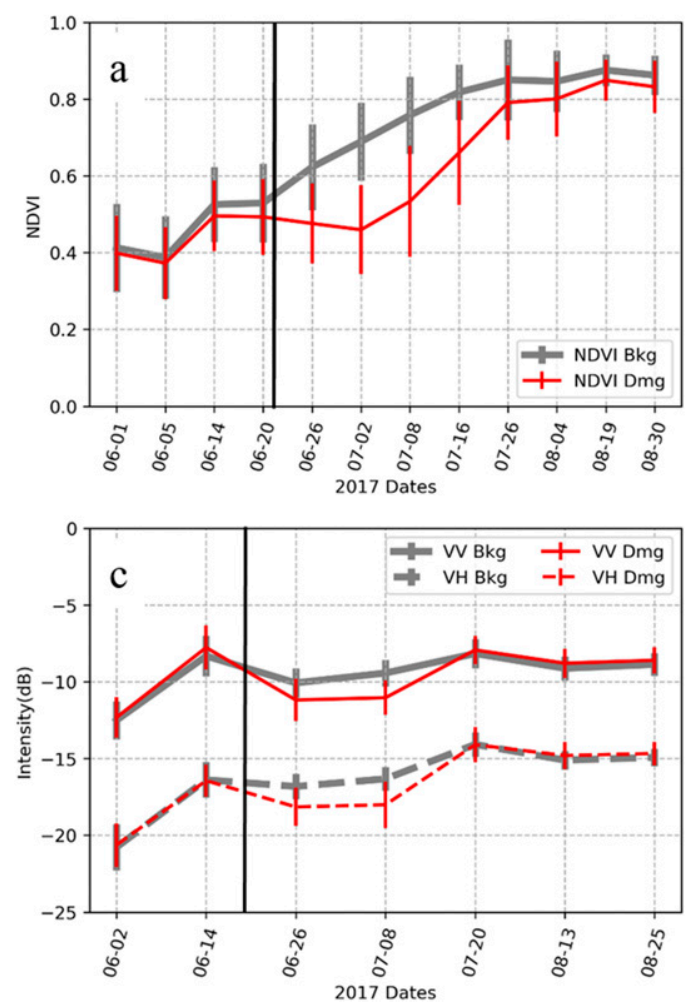

Soybean
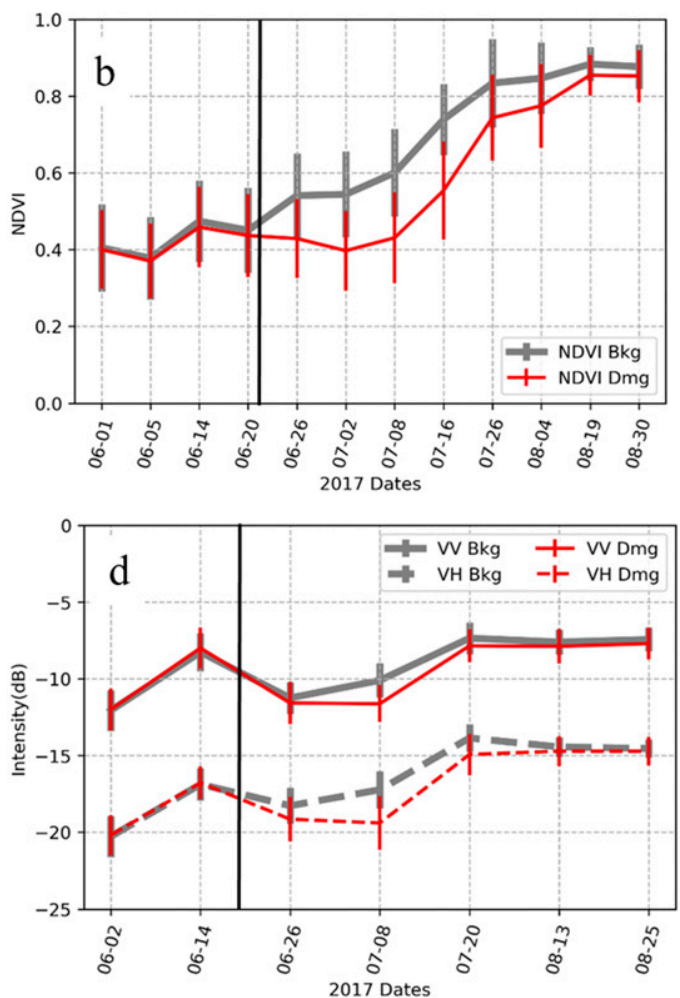

FIG. 3. (a) Time series for NDVI for the damaged and background areas of (a) corn and (b) soybean crops identified by the 2017 CDL. The black vertical line represents the approximate time that the damaging thunderstorm occurred. Also shown are time series of the co- and cross polarizations for the damaged and background areas of the 2017 CDL identified (c) corn and (d) soybean damaged and background areas.

significant at the 0.05 threshold despite visible scarring. Three daily observations from 2 to 16 July 2017 resulted in statistically significant differences between the sampled mean NDVI of the damaged corn crops, while the mean NDVI differences for soybeans were only significant for observations on 16 July 2017. While individual days may not meet a 0.05 threshold for significance, observations of lower NDVI within the scarred region are attributable to storm-damaged vegetation.

The mean NDVI values of the damaged corn and soybean pixels increased from 0.46 to 0.79 and from 0.40 to 0.74 , respectively, during the period of 2 to 26 July 2017 (Table 1). Based upon imagery, time of year, and observed greenness, it is likely the majority of the corn crops were not replanted. The mean NDVI values for the background areas for corn and soybean exceeded 0.8 by the end of July into early August while peaking later in August, consistent with Wardlow and Egbert (2008). Mean NDVI values of the damaged areas approached those of the background values by the 19 August 2017 acquisition. As the damaged areas of the corn and soybeans recovered and matured during the growing season, the standard deviations of NDVI for both crops were larger than the standard deviations observed in the undamaged background areas (Figs. 3a,b, Table 1). These larger standard deviations indicate the varying degrees of plant health and maturity inside the damaged agricultural areas. Changnon (1977) found similar results, noting varying degrees of damage within surveyed hail swaths, some even completely unaffected. The narrowing of the mean NDVI values between the damaged and undamaged areas led to none of the observations at the end of July being statistically significant.

Sentinel-1 VV and VH backscatter images acquired 5 days after the hailstorm on 26 June 2017 are shown in Fig. 4. The University of Minnesota (UM) Extension surveyed hail-damaged fields in western Minnesota as a result of a separate storm event 10 days earlier (10-11 June 2017) that produced similar hail and wind sizes as those observed on 22 June. Here, we assume that their photographs are representative of vegetation height, volume, and structure sampled for case study 1 . SAR backscatter was dominated by interactions between 

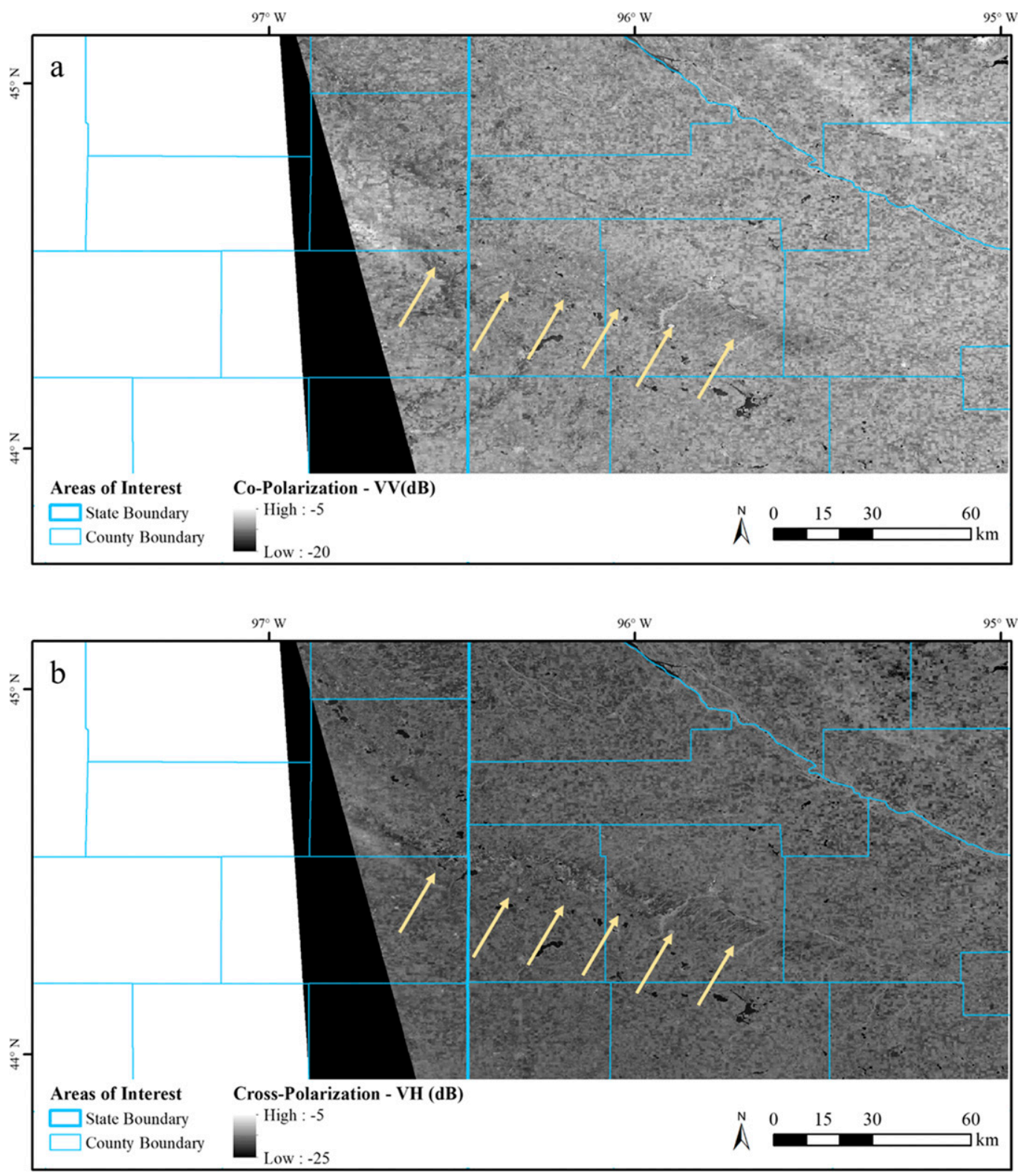

FIG. 4. Sentinel-1 (a) copolarization (VV) and (b) cross-polarization (VH) intensity images over the domain of case study 1 acquired on 26 Jun 2017. Image source: ASF DAAC from 2019, contains modified Copernicus Sentinel data accessed in 2019, processed by ESA.

the radar signal, early stage crops with sparse leaves and stems, and the soil surface as shown in the UM Extension photography (Figs. 5b,c). The photographs showed hail-damaged corn, with greater structure and volume prone to damage than soybean crops (Fig. 5; Coulter et al. 2017). In Fig. 3b and Table 2, the background area of the copolarized backscatter (VV) for both crop types is dominated by pixels that exhibit higher mean values $(-10.7 \mathrm{~dB})$ from the combined surface scattering of rough soil and plant structure than in the cross-polarized return ( $\mathrm{VH}$ of $-17.5 \mathrm{~dB}$; Fig. $3 \mathrm{~b}$, Table 2).
As in the case of the NDVI, the time series comparisons of the damaged and undamaged background areas for CDL-identified corn and soybean crops in VV and VH polarizations reveal a similar pattern, where the damaged areas and undamaged areas are similar in backscatter, the damaging hail causes the values to diverge for a time before the damaged areas are able to catch back up to the undamaged areas in terms of backscatter (Figs. 4c,d, Table 2). Moreover, it is evident that the VV and VH polarizations track and portray the various growth stages of the two crop types. Low backscatter 

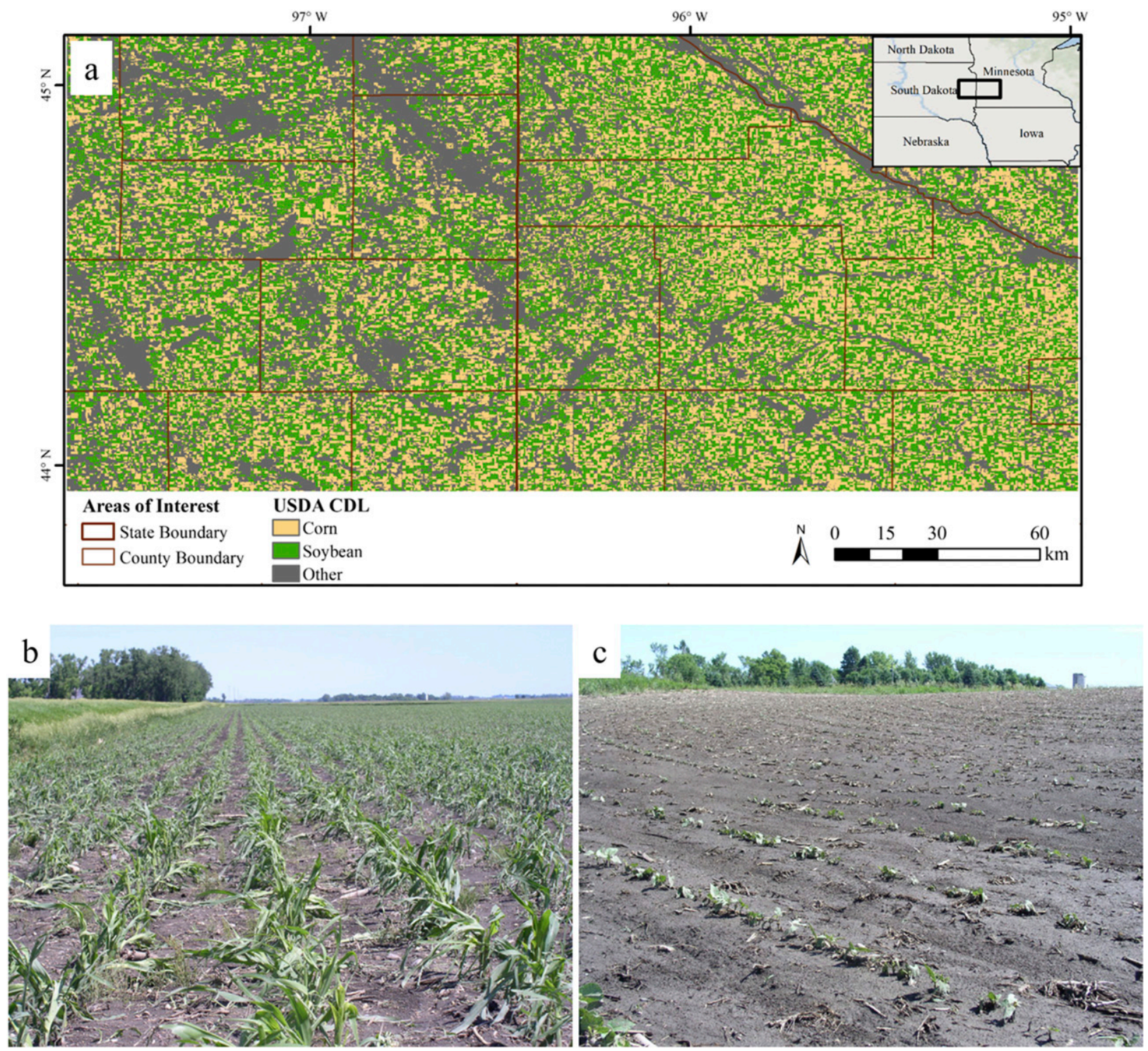

FIG. 5. (a) The 2017 USDA CDL for the domain of the 21 Jun 2017 event. (b) Corn crops from Minnesota after thunderstorms brought damaging winds and large hail in mid-June 2017. (c) As in (b), but soybean crops are present; (b) and (c) are from a separate event that occurred 11 Jun 2017 in western Minnesota. Both pictures are to represent similar crop conditions for the 21 Jun 2017 event [the figure is provided through the courtesy of Coulter et al. (2017)].

values are expected for the 2 June acquisition considering the early growth stage of the observed crops (corn and soybean emergence phase; Jiao et al. 2011) and lack of volumetric scattering interactions among the radar signal, the soil surface, and sparse plant structure.

During the first two SAR acquisition intervals prior to the hailstorm (2 and 14 June), the mean backscatter values (damaged and undamaged areas) gradually increased in the corn crops in the $\mathrm{VV}$ and $\mathrm{VH}$ polarizations by 4.4 and $4.3 \mathrm{~dB}$, respectively, and for the soybean crops those polarizations increased by 4.3 and $3.4 \mathrm{~dB}$, respectively. The increase in backscatter for the 14 June acquisition is expected following further crop growth and canopy development, creating a suitable condition for surface and volumetric scattering interactions (Jiao et al. 2011; McNairn et al. 2014). Note that between the 14 and 26 June Sentinel-1 observations the undamaged areas of both crops had a slight backscatter decline, which would contradict the findings of increasing backscatter during growth of Jiao et al. (2011) and McNairn et al. (2014). Because there was no additional SAR acquisition between these dates, it could be hypothesized that, although the early season growth and structure of the undamaged background areas did not see the impacts 
TABLE 2. Mean copolarization (VV) and cross-polarization (VH) backscatter values, standard deviations, $\mathrm{z}$ scores, and $p$ values for both the damaged and undamaged background areas of corn and soybean crops for the 21 Jun 2017 South Dakota and Minnesota case study.

\begin{tabular}{|c|c|c|c|c|c|c|c|c|c|c|c|c|}
\hline \multirow{2}{*}{$\begin{array}{l}\text { Sentinel-1 } \\
\text { date }\end{array}$} & \multicolumn{6}{|c|}{ VV (dB) } & \multicolumn{6}{|c|}{$\mathrm{VH}(\mathrm{dB})$} \\
\hline & Dmg mean & Dmg std & Bkg mean & Bkg std & $z$ score & $p$ value & Dmg mean & Dmg std & Bkg mean & Bkg std & $z$ score & $p$ value \\
\hline \multicolumn{13}{|c|}{ CDL corn areas } \\
\hline 2 Jun & -12.32 & 1.33 & -12.50 & 1.24 & 0.14 & 0.44 & -20.63 & 1.42 & -20.77 & 1.50 & 0.07 & 0.47 \\
\hline 14 Jun & -7.77 & 1.43 & -8.32 & 1.33 & 0.43 & 0.33 & -16.44 & 1.05 & -16.38 & 1.16 & -0.06 & 0.48 \\
\hline 26 Jun & -11.18 & 1.39 & -10.07 & 0.95 & -1.07 & 0.14 & -18.15 & 1.24 & -16.82 & 0.83 & -1.44 & 0.08 \\
\hline $8 \mathrm{Jul}$ & -11.03 & 1.12 & -9.43 & 0.87 & -1.74 & 0.04 & -18.01 & 1.50 & -16.32 & 0.77 & -1.97 & 0.02 \\
\hline $20 \mathrm{Jul}$ & -7.93 & 0.91 & -8.16 & 0.96 & 0.24 & 0.40 & -14.10 & 1.15 & -14.08 & 0.81 & 0.02 & 0.49 \\
\hline 13 Aug & -8.79 & 0.96 & -9.12 & 0.79 & 0.44 & 0.33 & -14.80 & 0.89 & -15.10 & 0.60 & 0.54 & 0.29 \\
\hline 25 Aug & -8.60 & 0.85 & -8.87 & 0.74 & 0.39 & 0.35 & -14.67 & 0.76 & -14.92 & 0.55 & 0.50 & 0.31 \\
\hline \multicolumn{13}{|c|}{ CDL soybean areas } \\
\hline 2 Jun & -12.00 & 1.36 & -12.05 & 1.32 & 0.04 & 0.48 & -20.18 & 1.31 & -20.27 & 1.34 & 0.06 & 0.48 \\
\hline 14 Jun & -8.00 & 1.34 & -8.26 & 1.25 & 0.22 & 0.41 & -16.77 & 1.07 & -16.87 & 1.05 & 0.10 & 0.46 \\
\hline 26 Jun & -11.58 & 1.37 & -11.25 & 1.04 & -0.26 & 0.40 & -19.14 & 1.46 & -18.26 & 1.17 & -0.70 & 0.24 \\
\hline $8 \mathrm{Jul}$ & -11.62 & 1.20 & -10.10 & 1.12 & -1.41 & 0.08 & -19.39 & 1.76 & -17.22 & 1.22 & -1.60 & 0.05 \\
\hline $20 \mathrm{Jul}$ & -7.85 & 1.08 & -7.35 & 1.04 & -0.48 & 0.32 & -14.93 & 1.35 & -13.85 & 0.90 & -1.12 & 0.13 \\
\hline 13 Aug & -7.88 & 1.13 & -7.61 & 0.82 & -0.32 & 0.38 & -14.71 & 0.97 & -14.44 & 0.63 & -0.40 & 0.34 \\
\hline 25 Aug & -7.70 & 1.03 & -7.44 & 0.77 & -0.32 & 0.37 & -14.71 & 0.91 & -14.54 & 0.60 & -0.25 & 0.40 \\
\hline
\end{tabular}

like damaged areas, they could have still been susceptible to the effects (i.e., high wind temporarily changing the viewing geometry) of intense thunderstorms.

The hail event on 22 June 2017 created a large change in backscatter within the damage polygon area (Figs. 3c,d, Table 2). The mean VV and VH backscatter differences between the damaged and undamaged areas for both crop types for the 26 June 2017 acquisition declined by 0.8 and $1.0 \mathrm{~dB}$, respectively, from the 14 June 2017 acquisition. This low decline in both polarizations is attributed to the infancy of the growth stage of the affected crops and the lack of well-developed leaf structure, and the contribution of the backscatter from the soil surface on the overall backscatter signature. The magnitude of the difference in mean backscatter for the damaged and background areas in the corn and soybean crops in the 26 June acquisition in the $\mathrm{VV}$ polarization is 1.1 and $0.3 \mathrm{~dB}$, respectively, and in the $\mathrm{VH}$ polarization it is 1.3 and $0.9 \mathrm{~dB}$ for corn and soybeans, respectively, as a result of the early crop growth stages. There were no statistically significant differences at the 0.05 threshold observed in either polarization for the two crop type in the 26 June 2017 SAR observations. The magnitudes of the mean backscatter differences increased for the 8 July 2017 acquisition for the two crops. The mean backscatter difference for corn and soybean crops was 1.7 and $1.4 \mathrm{~dB}$, respectively, in the $\mathrm{VV}$ polarization and was 1.6 and $2.2 \mathrm{~dB}$, respectively, in the $\mathrm{VH}$ polarization. This mean backscatter difference observed in the VV and VH polarization for the corn and in the $\mathrm{VH}$ polarization for the soybean crops was the statistically significant observations at the 0.05 threshold in case study 1 . From 26 June
2017 to 8 July 2017, the change in the mean background backscatter for the $\mathrm{VV}$ and $\mathrm{VH}$ polarizations were 0.9 and $0.7 \mathrm{~dB}$, respectively. The soybean crops contributed most to those increases in mean background backscatter, as the $\mathrm{VV}$ and $\mathrm{VH}$ polarizations increased by 1.2 and $1.0 \mathrm{~dB}$, respectively. This would suggest that the soybean crops developed more canopy structure, something that similar studies have noted (Jiao et al. 2011; Cable et al. 2014; McNairn et al. 2014). For example, Cable et al. (2014) observed a higher backscatter increment with growth and development for soybean crops when compared with others and attributed the resulting increment to large broad leaf structure and lateral spread that created an increase in volumetric scattering.

The difference in mean backscatter magnitude for VV and $\mathrm{VH}$ polarizations in the hail-affected and unaffected background decreases toward the 20 July 2017 acquisition for the VV and VH mean backscatter for the corn and soybean crops. This decreasing difference in the mean backscatter of the two polarizations indicates that the amount of physical volume and structure of the two crop types appears recovered and of similar status for both the damaged and background areas (Figs. 4c,d). Contrary to the pattern noted on the NDVI time series, the increase in biomass has reduced the penetration of the C-band SAR signal beyond the top canopy surface and resulted in the saturation of the backscatter return (value) beyond the 20 July acquisition. Similar relationships between increase in biomass and backscatter return have been noted in several studies (Paloscia et al. 1999; Ferrazzoli 2002; Abdikan et al. 2018). Ferrazzoli (2002) used airborne data to investigate the relationship 
between C-band $\mathrm{HH}$ and VV backscatter and increasing leaf area index (LAI) and noted that the SAR backscatter saturated once LAI reached a value of 2-3. Jones et al. (2003) made field measurements of the LAI of soybean crops at experimental locations in Minnesota and Wisconsin at different times [41, 54, and 69 days after planting (DAP)] and varying cropping system and soil types. Measured mean LAI values ranged from 1.4 (41 DAP) to 4.6 (69 DAP) late in the growing season. Therefore, it is not surprising that SAR backscatter saturates late in the growing season with decreased sensitivity while NDVI continues to show changes over time in both the damaged area and undamaged background.

\section{b. 7 August 2018-South-central Nebraska}

A strong thunderstorm with winds in excess of $26 \mathrm{~m} \mathrm{~s}^{-1}\left(60 \mathrm{mi} \mathrm{h}^{-1}\right)$ and SPC reports of hail sizes ranging from 2.54 to $5.08 \mathrm{~cm}$ (1-2 in.) and a $9.28 \mathrm{~cm}$ (3.65 in.) maximum MESH value was observed as it moved through south-central Nebraska on 7 August 2018. Two segments of hail damage with a combined length of nearly $90 \mathrm{~km}$ and a width of 3-6 km were seen in singleday MODIS NDVI on 12 August 2018 (Fig. 6). The University of Nebraska Extension (Ingram 2018) documented a hailstorm event, with similar wind and hail reports, in Howard County (northwest of the study area) on 16 August 2018 that produced a partial toppling of corn crops, which we believe represent conditions of damaged crops following the 7 August hailstorm event (Fig. 7).

Consistent with past studies and the South Dakota/ Minnesota case study highlighted above, mean NDVI values across the two crop types within the damage polygon dropped and continued to decline with time. With the timing of this case study late in the growing season, both the damaged and background areas of the corn and soybean crops were nearly identical in their trends through 2 August 2018 (Figs. 8a,b, Table 3). The mean NDVI values of the damaged and background areas of the corn and soybean crops were 0.86 and 0.88 respectively, prior to the occurrence of the hail damage. The first poststorm NDVI acquisition occurred on 9 August 2018, where the mean NDVI of damaged corn and soybean areas were reduced to 0.76 and 0.75 , respectively. By 12 August 2018, the mean NDVI for of corn and soybeans decreased to 0.67 and 0.69 , respectively, and both continued to decrease through the 24 August MODIS acquisition (Figs. 8a,b, Table 3). Differences between the damaged and background NDVI observations through 29 August were statistically significant for both crop types using the threshold of 0.05 . After 24 August 2018, the NDVI in both the damaged and background areas began to decrease, indicating that the undamaged crops in the background had reached the end of their life cycle, having started to wilt/brown, and remnants harvested or fields cleared to expose a significantly greater amount of bare soil (Figs. 8a,b, Table 3).

The time series of backscatter reflects a similar pattern as case study 1 in South Dakota and Minnesota especially with the behavior of the background vegetation (Figs. 8c,d, Table 4). Here, the corn crops developed a dense canopy structure beginning 7 July that resulted in the saturation of the backscatter return in both $\mathrm{VV}$ and $\mathrm{VH}$ for a long duration of the crop cycle up until the hail event. Similarly, the VV and VH time series for the soybean crops show an early-season increase followed by a steady value as the C-band returns saturate. A key difference occurs following the hail event: here, corn pixels in the hail-affected region produced an increase of $0.4 \mathrm{~dB}$ for the VV polarization and $1.4 \mathrm{~dB}$ for the $\mathrm{VH}$ polarization. The damaged soybean crops saw a mean backscatter difference between the damaged and undamaged background areas increase $0.8 \mathrm{~dB}$ for the copolarization and $2.5 \mathrm{~dB}$ for the cross polarization (Figs. 8c,d, Table 4). The hail event occurred during midJuly to mid-August, a period of highest water demand in growth stages of corn (tassel, silking, and kernel blister) and soybean (flower and pod development) crops in Nebraska (Kranz et al. 2008; Kranz and Specht 2012). These lateseason growth stages correspond to high MODIS NDVI as well as VV and VH backscatter values (Fig. 8).

We hypothesize that increases in SAR backscatter within the damage region are attributable to the combined effects of double-bounce and volumetric scattering mechanisms through the partial toppling of crops and the presence of saturated soils and standing water attributed to irrigation. In Nebraska, groundwater-based irrigation is a practice applied on nearly half of the cropland acres in the state (Johnson et al. 2011). Radarestimated rainfall and local daily climatology reports of the investigated area before and during the time of SAR brightening within the damage region (12 August) show a trace amount of precipitation (NCEI 2019). Moreover, the SAR images were acquired during the late afternoon, and hence the possibility of water droplets from afternoon irrigation impacting (increasing) the backscatter is low. The increase in backscatter (brightening) over the hail-affected area has also been verified through neighboring track acquisitions with varying geometry that were acquired after the hailstorm.

Double-bounce surface scattering resulting from interactions of the standing water in the fields, partially toppled, and flanking unaffected crop structures (Fig. 9) could explain the increase in mean backscatter (brightening $)$ in the $\mathrm{VV}$ polarization for both corn $(0.4 \mathrm{~dB})$ and 

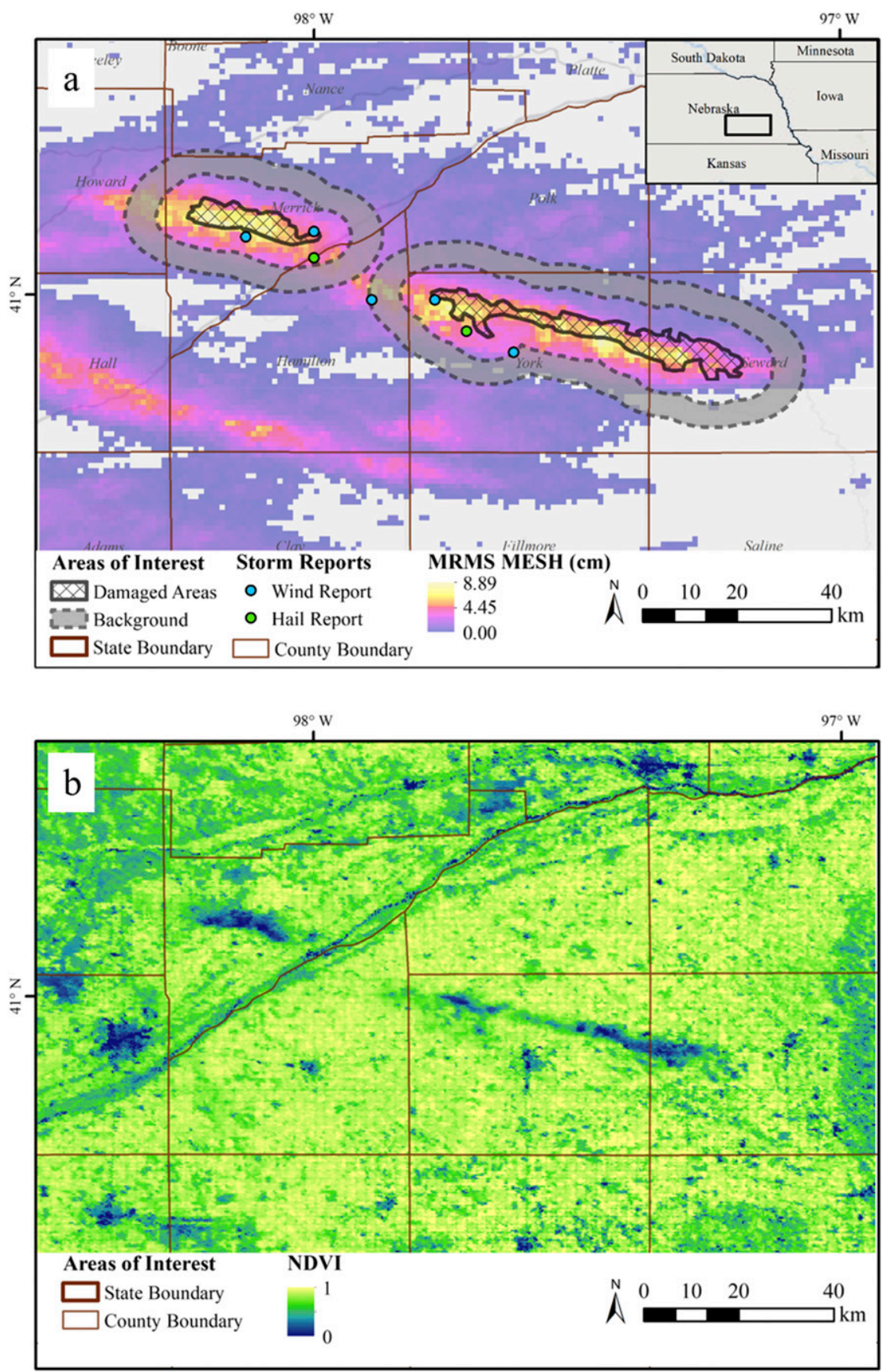

FIG. 6. (a) As in Fig. 2a, but the MRMS MESH product is valid from 1200 UTC 6 Aug to 〜1200 UTC 7 Aug 2018. (b) Single-day NDVI for 12 Aug 2018.

soybeans $(0.8 \mathrm{~dB})$ relative to their undamaged background on 12 August 2018. In the $\mathrm{VH}$ polarization, larger increases occurred through combination of volumetric and doublebounce surface scattering mechanisms (corn: $1.2 \mathrm{~dB}$; soybean: $2.5 \mathrm{~dB}$; Fig. 9; Table 4). Greater increases in VH-polarization backscatter are consistent with past research (Karjalainen et al. 2008; Hong and Wdowinski
2014; Li and Wang 2018). The differences in the mean backscatter values between the background and damaged areas in the $\mathrm{VH}$ polarization from the two SAR acquisitions in August 2018 were both statistically significant for both crops at the 0.05 threshold, whereas the two VV polarization did not meet the 0.05 threshold for either crop. 

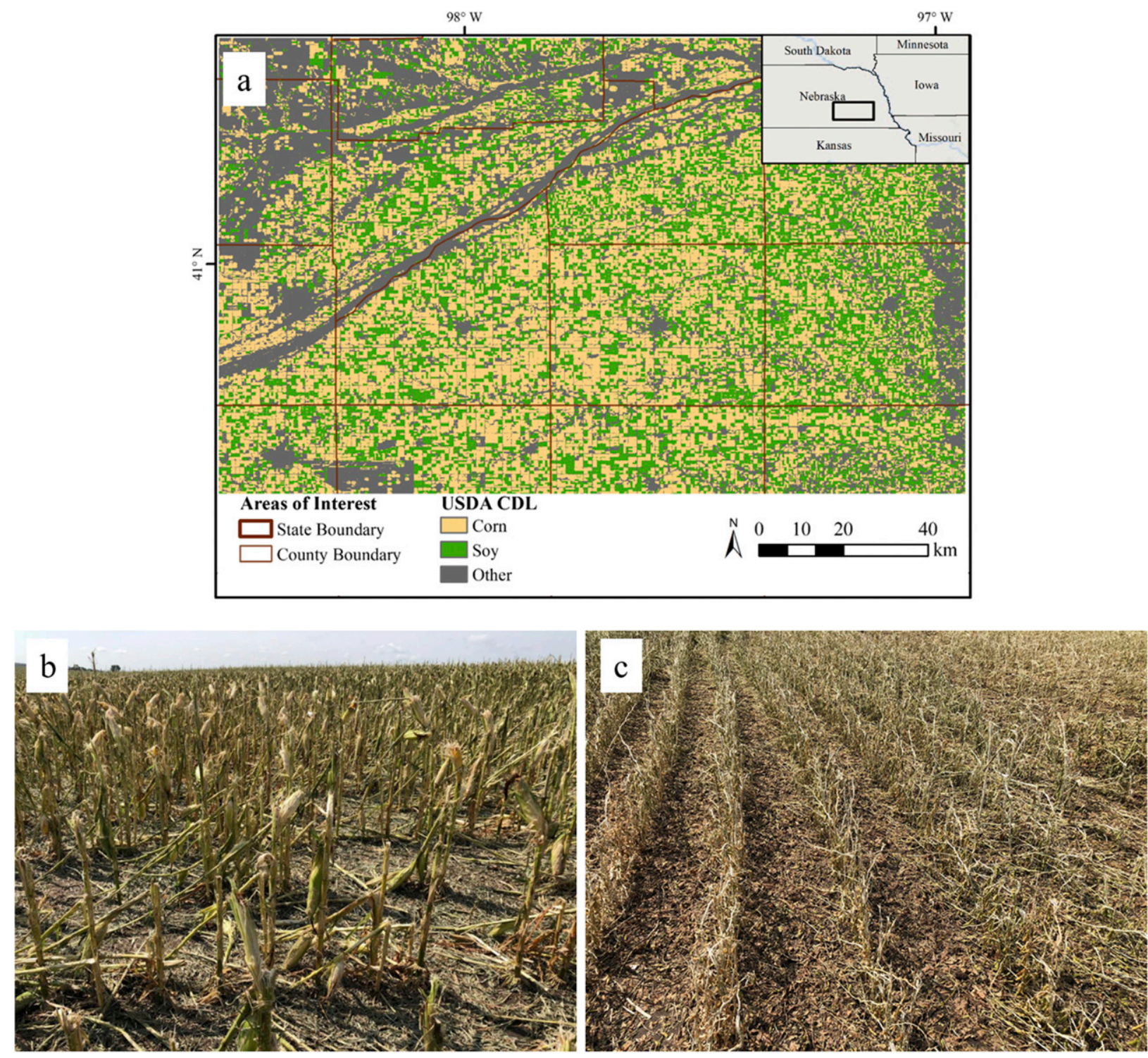

FIG. 7. (a) As in Fig. 3a, but 2018 CDL for the domain of the 6 Aug 2018 event (case study 2). (b) Corn crops from Nebraska after thunderstorms brought damaging winds and large hail in mid-August 2018. (c) As in (b), but soybean crops are present; (b) and (c) are from a separate event that occurred on 16 Aug 2018 just northwest of the 6 Aug 2018 event in Nebraska. Both pictures are to represent similar crop conditions poststorm for the 6 Aug 2018 event, and both are from Ingram (2018).

CCD procedures were applied to three SAR images to offer an additional method to validate the inference of change in the individual SAR images and backscatter attributed to the hailstorm. Pixels with coherence less than 0.3 in the pre- and posthailstorm pair (31 July and 12 August 2018) were initially identified as possible hailaffected pixels. The 0.3 coherence threshold value was selected considering that the study area is covered by agricultural crops whose continuous growth alters the target geometry and C-band signal interaction, introducing phase noise and generating incoherent/low coherent pixels. To exclude low coherence pixels attributed to sources other than the hailstorm, a second prehailstorm coherence product was generated using the prehailstorm image SLC acquisitions (19 and 31 July 2018). Pixels with low coherence values (less than 0.3) in the two pairs of products were deemed to be caused by incidents or processes other than the hailstorm and subsequently were excluded from the final output (Fig. 10). Figure 10 shows a good spatial correspondence between the MESHderived hailstorm track and the low coherence pixels that represent the hail-affected crops. Pixels along the track of the storm underwent a significant decline in coherence values (up to $90 \%$ drop in some cases) and such 
Corn
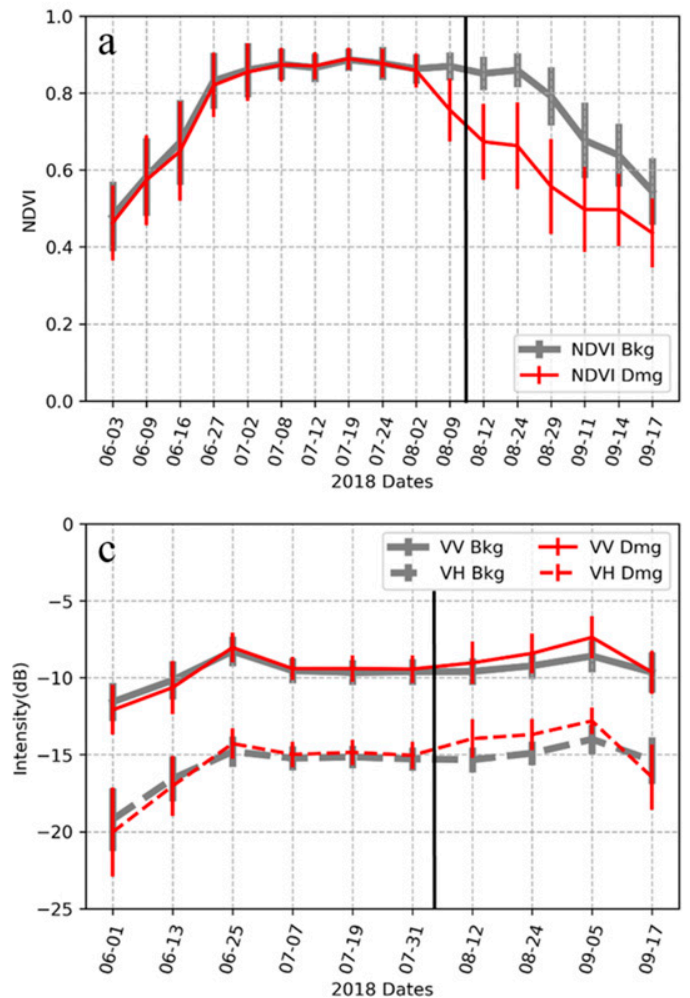

Soybean
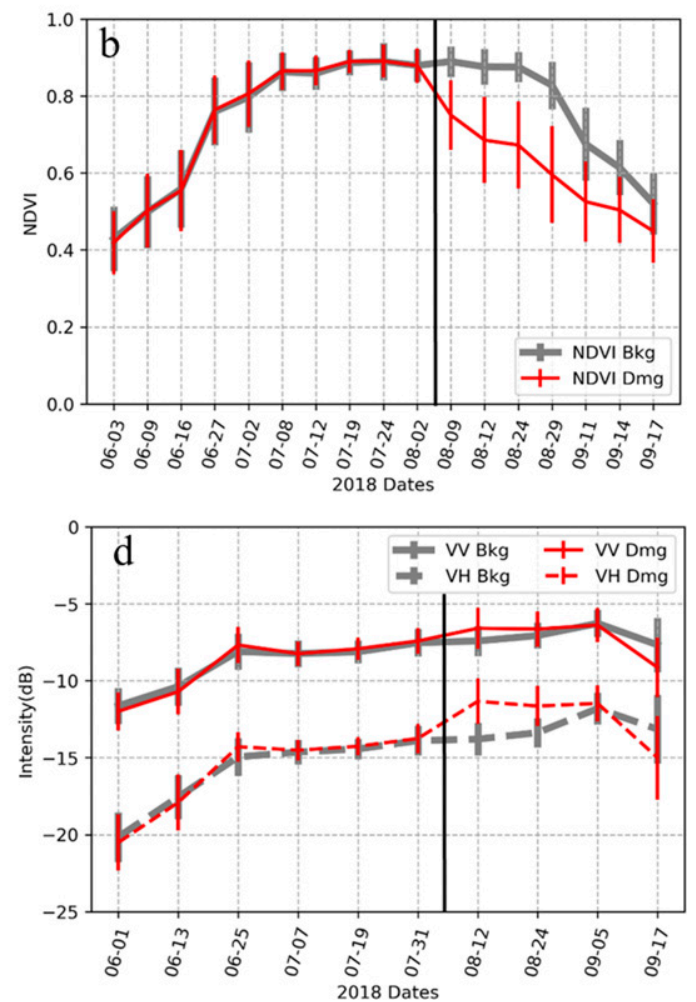

FIG. 8. Time series for NDVI for the damaged and background areas of (a) corn and (b) soybean crops identified by the 2018 CDL. The black vertical line represents the approximate time the damaging thunderstorm occurred. Also shown are time series of the co- and cross polarizations for the damaged and background areas of the 2018 CDL identified (c) corn and (d) soybean damaged and background areas.

drop within a short period (12 days) can only be attributed to impacts of hail rather than the agricultural growth cycle of the crops.

Analysis for both case studies demonstrate that SAR is capable of identifying local changes in backscatter attributable to hail damage though different types of scattering mechanisms, and darkening or brightening may result from the combination of storm damage and other factors. Anomalies between the hail-affected region and immediate background map impacted areas similar to traditional optical approaches and allow identification of the affected area.

\section{Summary and future work}

Qualitative and quantitative analyses of MODIS and Sentinel-1 SAR backscatter were used to characterize the spatial extent of hail damage swaths and observe the time evolution of these parameters for CDL-designated corn and soybean crops in the central United States. Two case studies of hailstorm events during the early and late growing seasons were used to characterize changes in NDVI and corresponding SAR backscatter as a result of hail damage when compared to their local background. Key findings are summarized below:

1) NDVI time series analyses of the hail-damaged areas revealed trends related to the timing of hail damage within the growing season. In early season event (South Dakota and Minnesota), the mean NDVI values of the hail-affected crops rebounded to approach values of the undamaged background areas later in the season. The late-season event (Nebraska) resulted in initial NDVI reductions of up to 0.13 that did not return to the corresponding background values prior to the end of season harvest period.

2) Understanding and analysis of changes in amplitude and phase were used to qualitatively identify and map the hail damage swaths using SAR backscatter and coherence methods. Backscatter time series analyses of SAR imagery captured various growing stages along with limits on the continued increase in backscatter attributed here to dense vegetation canopies that limit penetration by available C-band observations. In the early season case, hail damage produced a slight drop in backscatter value relative 
TABLE 3. As in Table 1, but for the 6 Aug 2018 central Nebraska case study.

\begin{tabular}{|c|c|c|c|c|c|c|c|c|c|c|c|c|}
\hline \multirow{2}{*}{$\begin{array}{c}\text { MODIS } \\
\text { date }\end{array}$} & \multicolumn{6}{|c|}{ Corn CDL areas } & \multicolumn{6}{|c|}{ Soybean CDL areas } \\
\hline & Dmg mean & Dmg std & Bkg mean & Bkg std & $z$ score & $p$ value & Dmg mean & Dmg std & Bkg mean & Bkg std & $z$ score & $p$ value \\
\hline 3 Jun & 0.46 & 0.10 & 0.48 & 0.09 & -0.20 & 0.42 & 0.42 & 0.08 & 0.43 & 0.08 & -0.12 & 0.45 \\
\hline 9 Jun & 0.57 & 0.12 & 0.58 & 0.10 & -0.09 & 0.46 & 0.50 & 0.10 & 0.50 & 0.09 & 0.05 & 0.48 \\
\hline 16 Jun & 0.65 & 0.13 & 0.67 & 0.11 & -0.22 & 0.41 & 0.55 & 0.11 & 0.56 & 0.10 & -0.03 & 0.49 \\
\hline 27 Jun & 0.82 & 0.08 & 0.83 & 0.07 & -0.16 & 0.43 & 0.76 & 0.09 & 0.76 & 0.09 & 0.06 & 0.47 \\
\hline $2 \mathrm{Jul}$ & 0.85 & 0.07 & 0.86 & 0.07 & -0.08 & 0.47 & 0.81 & 0.09 & 0.80 & 0.09 & 0.11 & 0.46 \\
\hline $8 \mathrm{Jul}$ & 0.87 & 0.04 & 0.87 & 0.04 & -0.04 & 0.48 & 0.87 & 0.05 & 0.86 & 0.05 & 0.05 & 0.48 \\
\hline $12 \mathrm{Jul}$ & 0.87 & 0.04 & 0.87 & 0.04 & 0.11 & 0.45 & 0.87 & 0.04 & 0.86 & 0.04 & 0.16 & 0.43 \\
\hline $19 \mathrm{Jul}$ & 0.89 & 0.03 & 0.89 & 0.03 & 0.09 & 0.46 & 0.89 & 0.03 & 0.89 & 0.03 & 0.10 & 0.46 \\
\hline $24 \mathrm{Jul}$ & 0.88 & 0.04 & 0.88 & 0.04 & -0.01 & 0.50 & 0.89 & 0.04 & 0.89 & 0.05 & 0.03 & 0.49 \\
\hline 2 Aug & 0.86 & 0.04 & 0.86 & 0.04 & -0.13 & 0.45 & 0.88 & 0.05 & 0.88 & 0.04 & 0.01 & 0.50 \\
\hline 9 Aug & 0.76 & 0.08 & 0.87 & 0.04 & -3.12 & 0.00 & 0.75 & 0.09 & 0.89 & 0.04 & -3.49 & 0.00 \\
\hline $12 \mathrm{Aug}$ & 0.67 & 0.10 & 0.85 & 0.04 & -4.10 & 0.00 & 0.69 & 0.11 & 0.88 & 0.05 & -4.12 & 0.00 \\
\hline 24 Aug & 0.66 & 0.11 & 0.86 & 0.04 & -4.49 & 0.00 & 0.67 & 0.11 & 0.88 & 0.04 & -5.16 & 0.00 \\
\hline $29 \mathrm{Aug}$ & 0.56 & 0.12 & 0.79 & 0.08 & -3.12 & 0.00 & 0.60 & 0.13 & 0.83 & 0.06 & -3.77 & 0.00 \\
\hline 11 Sep & 0.50 & 0.11 & 0.68 & 0.10 & -1.82 & 0.03 & 0.53 & 0.10 & 0.68 & 0.10 & -1.56 & 0.06 \\
\hline 14 Sep & 0.50 & 0.09 & 0.64 & 0.08 & -1.72 & 0.04 & 0.50 & 0.09 & 0.61 & 0.07 & -1.53 & 0.06 \\
\hline $17 \mathrm{Sep}$ & 0.44 & 0.09 & 0.54 & 0.09 & -1.24 & 0.11 & 0.45 & 0.08 & 0.52 & 0.08 & -0.88 & 0.19 \\
\hline
\end{tabular}

to the undamaged background in both polarizations (VV $0.8 \mathrm{~dB}$; VH $1.2 \mathrm{~dB}$ ). These relatively small changes were attributed to early growth stages of affected crops, greater exposure of soils, and the lack of welldeveloped plant structures and canopies. The second, late-season event produced a moderate increase in backscatter return ( VV 0.5-0.8 dB; VH 1.2-2.5 dB) in the affected crops. Through analysis of available meteorological data, common agricultural irrigation practices, and photographs corresponding to likely crop damage, we hypothesize that this brightening (increase) in backscatter results from the combined effects of standing water/water-saturated soil and crop structure as increased returns through additional

TABLE 4. As in Table 2, but for the 6 Aug 2018 central Nebraska case study.

\begin{tabular}{|c|c|c|c|c|c|c|c|c|c|c|c|c|}
\hline \multirow{2}{*}{$\begin{array}{l}\text { Sentinel-1 } \\
\text { date }\end{array}$} & \multicolumn{6}{|c|}{$\mathrm{VV}(\mathrm{dB})$} & \multicolumn{6}{|c|}{$\mathrm{VH}(\mathrm{dB})$} \\
\hline & Dmg mean & Dmg std & Bkg mean & Bkg std & $z$ score & $p$ value & Dmg mean & Dmg std & Bkg mean & Bkg std & $z$ score & $p$ value \\
\hline \multicolumn{13}{|c|}{ CDL corn areas } \\
\hline $1 \mathrm{Jun}$ & -12.09 & 1.61 & -11.57 & 1.24 & -0.36 & 0.36 & -20.03 & 2.88 & -19.21 & 2.05 & -0.32 & 0.38 \\
\hline 13 Jun & -10.64 & 1.72 & -10.16 & 1.25 & -0.34 & 0.37 & -17.03 & 1.95 & -16.56 & 1.46 & -0.31 & 0.38 \\
\hline 25 Jun & -8.03 & 0.96 & -8.27 & 0.96 & 0.26 & 0.40 & -14.28 & 0.99 & -14.79 & 1.00 & 0.54 & 0.30 \\
\hline $7 \mathrm{Jul}$ & -9.40 & 0.76 & -9.54 & 0.81 & 0.16 & 0.44 & -14.98 & 0.83 & -15.23 & 0.78 & 0.32 & 0.37 \\
\hline $19 \mathrm{Jul}$ & -9.40 & 0.87 & -9.66 & 0.81 & 0.31 & 0.38 & -14.85 & 0.83 & -15.15 & 0.73 & 0.41 & 0.34 \\
\hline $31 \mathrm{Jul}$ & -9.44 & 0.91 & -9.62 & 0.85 & 0.21 & 0.42 & -15.04 & 0.87 & -15.27 & 0.75 & 0.31 & 0.38 \\
\hline $12 \mathrm{Aug}$ & -9.03 & 1.38 & -9.59 & 0.86 & 0.75 & 0.23 & -13.96 & 1.25 & -15.33 & 0.81 & 1.85 & 0.03 \\
\hline 24 Aug & -8.41 & 1.29 & -9.22 & 0.85 & 1.03 & 0.15 & -13.69 & 1.03 & -14.90 & 0.78 & 1.66 & 0.05 \\
\hline 5 Sep & -7.38 & 1.37 & -8.59 & 1.04 & 1.24 & 0.11 & -12.81 & 0.87 & -13.99 & 0.97 & 1.25 & 0.11 \\
\hline 17 Sep & -9.64 & 1.39 & -9.64 & 1.31 & 0.01 & 0.50 & -16.46 & 2.12 & -15.38 & 1.51 & -0.61 & 0.27 \\
\hline \multicolumn{13}{|c|}{ CDL soybean areas } \\
\hline 1 Jun & -11.99 & 1.23 & -11.63 & 1.18 & -0.28 & 0.39 & -20.52 & 1.82 & -20.15 & 1.62 & -0.18 & 0.43 \\
\hline 13 Jun & -10.71 & 1.50 & -10.38 & 1.23 & -0.24 & 0.40 & -17.91 & 1.81 & -17.56 & 1.44 & -0.21 & 0.42 \\
\hline 25 Jun & -7.68 & 1.19 & -8.10 & 1.18 & 0.37 & 0.35 & -14.29 & 0.97 & -14.94 & 1.23 & 0.55 & 0.29 \\
\hline $7 \mathrm{Jul}$ & -8.24 & 0.78 & -8.24 & 0.86 & -0.02 & 0.49 & -14.51 & 0.67 & -14.64 & 0.79 & 0.14 & 0.44 \\
\hline $19 \mathrm{Jul}$ & -7.92 & 0.73 & -8.12 & 0.74 & 0.27 & 0.39 & -14.26 & 0.59 & -14.43 & 0.67 & 0.26 & 0.40 \\
\hline $31 \mathrm{Jul}$ & -7.42 & 0.84 & -7.53 & 0.89 & 0.13 & 0.45 & -13.75 & 0.95 & -13.89 & 0.96 & 0.14 & 0.44 \\
\hline 12 Aug & -6.59 & 1.34 & -7.41 & 0.99 & 0.98 & 0.16 & -11.34 & 1.47 & -13.79 & 1.06 & 2.73 & 0.00 \\
\hline 24 Aug & -6.64 & 1.13 & -7.06 & 0.84 & 0.58 & 0.28 & -11.64 & 1.31 & -13.37 & 0.95 & 2.06 & 0.02 \\
\hline 5 Sep & -6.39 & 1.11 & -6.27 & 0.88 & -0.11 & 0.46 & -11.47 & 1.19 & -11.80 & 1.04 & 0.36 & 0.36 \\
\hline 17 Sep & -9.13 & 1.92 & -7.67 & 1.77 & -0.77 & 0.22 & -15.00 & 2.71 & -13.15 & 2.24 & -0.78 & 0.22 \\
\hline
\end{tabular}



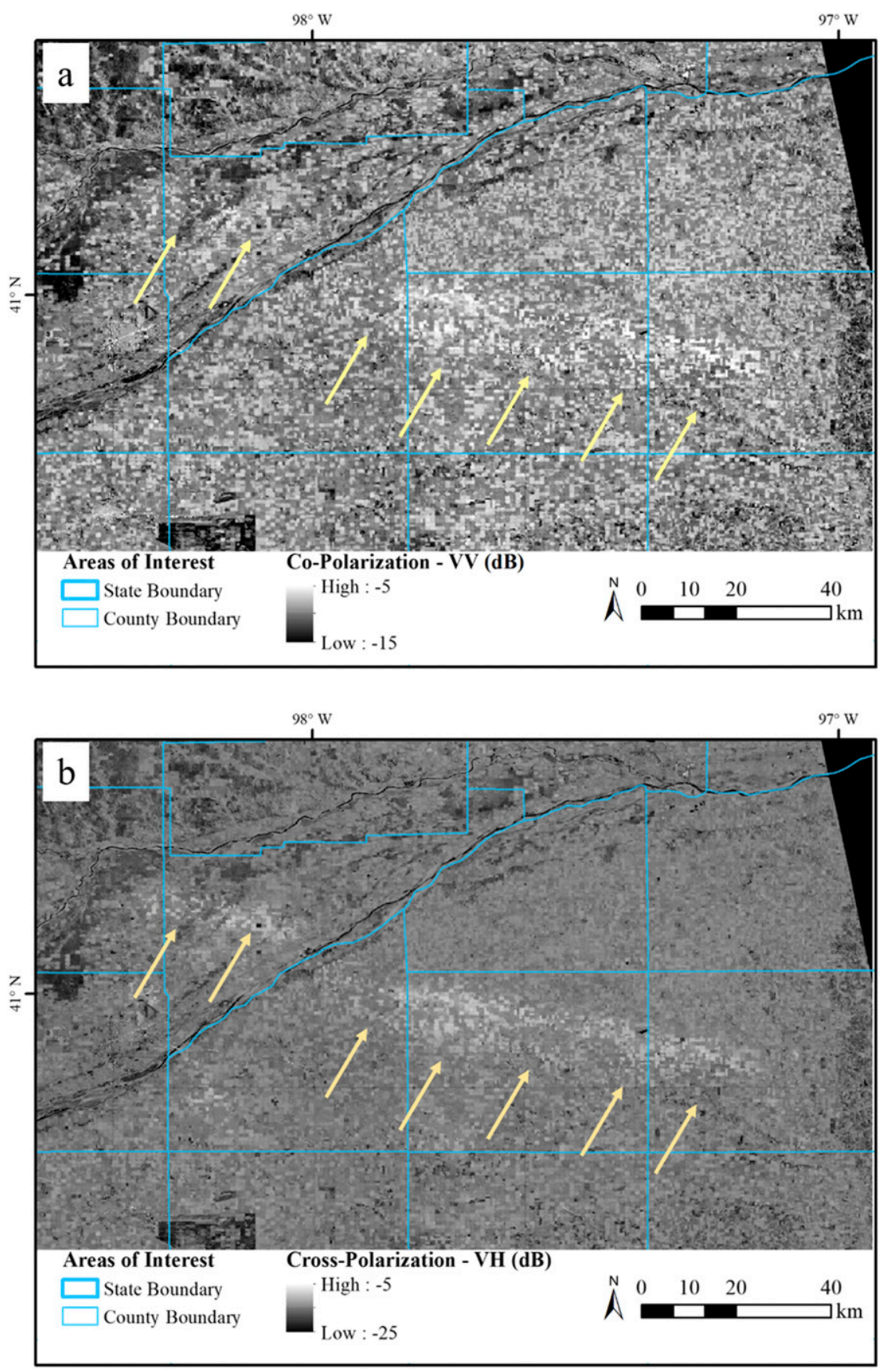

FIG. 9. Sentinel-1 (a) copolarization (VV) and (b) cross-polarization (VH) intensity images from 12 Aug 2018. Image source: ASF DAAC from 2019, contains modified Copernicus Sentinel data accessed in 2019, processed by ESA.

poststorm volume scattering. However, even though case studies differed in the direction of the change in backscatter, each hail event resulted in clear "scarring" present in the region, corresponding in space and time to past approaches examining vegetation indices and other approaches. In the late-season case study (south-central Nebraska), the CCD method was employed to further corroborate the hail damage observed and was able to map the extent of the hail swath by identifying pixels of substantially low coherence (less than 0.3) within the potential damage area. The footprint of CCD mapped hail swath spatially corresponds well with the NDVI- and MESH-derived extents. 


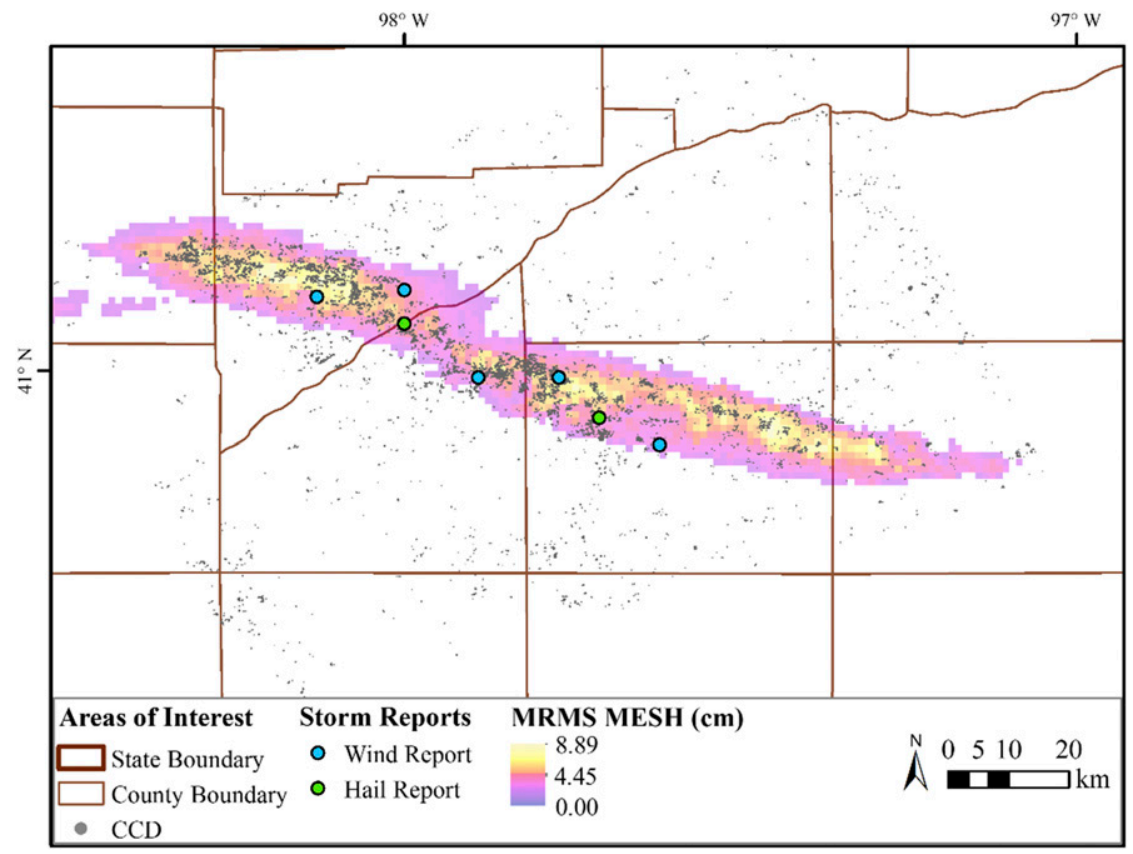

FIG. 10. CCD-based mapping of hail damage swath for the 2018 hailstorm event in south-central Nebraska. Pixels with low coherence values (less than 0.3 ) were identified as hail impacted areas. Prehailstorm pair (19-31 Jul) and pre- and posthailstorm pair (31 Jul-12 Aug) CCD products were combined to exclude low-coherence pixels attributed to causes/processes other than the hailstorm. Image source: ASF DAAC from 2019, contains modified Copernicus Sentinel data accessed in 2019, processed by ESA.

This study focused on if SAR could complement observations from optical remote sensors in identifying hail damage swaths and, as shown, was able to detect two damage swaths at various points in the growing season. Although damage can be detected, the direction of change in the SAR backscatter does not appear to follow a consistent direction (decrease) that has been routinely observed in NDVI. Additionally, this study did identify several limitations of using SAR backscatter observations when discerning these damage swaths that will require further analysis and study. Further investigations of the characterization and impacts on the scattering mechanisms from varying vegetation types, irrigation practices, weather conditions, SAR viewing angle, and additional SAR sensor wavelengths at various times in the growing season are still needed to fully understand the impacts of these environmental variables. Future examination of coherence and more advanced SAR processing techniques should be included, as will work looking at utilizing higher-resolution imagery from optical sensors (Landsat-8, Sentinel-2, and commercial datasets such as WorldView-2/3 and Planet) to examine changes closer to field scales, which will improve inference of SAR signatures.

Acknowledgments. The authors of this paper thank their colleagues at the University of Alaska Fairbanks and the NASA Alaska Satellite Facility DAAC for their assistance and friendship in the development of SAR knowledge and product generation. The authors also express appreciation to the three anonymous reviewers who provided constructive feedback to help improve the quality of this paper.

\section{REFERENCES}

Abdikan, S., A. Sekertekin, M. Ustunern, F. Balik Sanli, and R. Nasirzadehdizaji, 2018: Backscatter analysis using multitemporal Sentinel-1 SAR data for crop growth of maize in Konya Basin, Turkey. Int. Arch. Photogramm. Remote Sens. Spat. Inf. Sci., 42, 9-13, https://doi.org/10.5194/isprs-archivesXLII-3-9-2018.

Al-sharif, A., B. Pradhan, S. J. Hadi, and N. Mola, 2013: Revisiting methods and potentials of SAR change detection. Proc. World Congress on Engineering 2013, Vol. 3, London, United Kingdom, World Congress on Engineering, 1-7.

Bargiel, D., 2017: A new method for crop classification combining time series of radar images and crop phenology information. Remote Sens. Environ., 198, 369-383, https://doi.org/10.1016/ j.rse.2017.06.022.

Bell, J. R., and A. L. Molthan, 2016: Evaluation of approaches to identifying hail damage to crop vegetation using satellite imagery. J. Oper. Meteor., 4, 142-159, https://doi.org/10.15191/ nwajom.2016.0411.

Bentley, M. L., T. L. Mote, and P. Thebpanya, 2002: Using Landsat to identify thunderstorm damage in agricultural regions. Bull. Amer. Meteor. Soc., 83, 363-376, https://doi.org/10.1175/1520-0477-83.3.363. 
Boryan, C., Z. Yang, R. Mueller, and M. Craig, 2011: Monitoring US agriculture: The US Department of Agriculture, National Agricultural Statistics Service, Cropland Data Layer Program. Geocarto Int., 26, 341-358, https://doi.org/10.1080/ 10106049.2011.562309.

Bouaraba, A., A. Younsi, A. Belhadj Aissa, M. Acheroy, N. Milisavljevic, and D. Closson, 2012: Robust techniques for coherent change detection using COSMO-SkyMeD SAR images. Prog. Electromagn. Res. M, 22, 219-232, https:// doi.org/10.2528/PIERM11110707.

Cable, J. W., J. M. Kovacs, X. Jiao, and J. Shang, 2014: Agricultural monitoring in northeastern Ontario, Canada, using multi-temporal polarimetric RADARSAT-2 data. Remote Sens., 6, 23432371, https://doi.org/10.3390/rs6032343.

Canisius, F., and Coauthors, 2018: Tracking crop phenological development using multi-temporal polarimetric RADARSAT-2 data. Remote Sens. Environ., 210, 508-518, https://doi.org/ 10.1016/j.rse.2017.07.031.

Casey, J. A., S. E. L. Howell, A. Tivy, and C. Haas, 2016: Separability of sea ice types from wide swath C- and L-band synthetic aperture radar imagery acquired during the melt season. Remote Sens. Environ., 174, 314-328, https://doi.org/ 10.1016/j.rse.2015.12.021.

Changnon, S. A., Jr., 1977: The scales of hail. J. Appl. Meteor., 16, 626-648, https://doi.org/10.1175/1520-0450(1977)016<0626: $\mathrm{TSOH}>2.0 . \mathrm{CO} ; 2$.

— D. Changnon, and S. D. Hilberg, 2009: Hailstorms across the nation: An atlas about hail and its damages. Illinois State Water Survey Contract Rep. 2009-12, 92 pp.

Coulter, J., S. Naeve, and D. Nicolai, 2017: Hail damage to corn and soybean: Evaluation and replant options. University of Minnesota Extension, accessed 9 April 2019, https://blogcrop-news.extension.umn.edu/2017/06/hail-damage-to-cornand-soybean.html.

Ferrazzoli, P., 2002: SAR for agriculture: Advances, problems and prospects. Proc. Third Int. Symp. Retrieval of Bio-Geophysical Parameters from SAR Data for Land Applications, Sheffield, United Kingdom, ESA, SP 475, 47-56.

Forkuor, G., C. Conrad, M. Thiel, T. Ullmann, and E. Zoungrana, 2014: Integration of optical and synthetic aperture radar imagery for improving crop mapping in northwestern Benin, West Africa. Remote Sens., 6, 6472-6499, https://doi.org/ 10.3390/rs6076472.

Freeman, A., and S. L. Durden, 1998: A three-component scattering model for polarimetric SAR data. IEEE Trans. Geosci. Remote Sens., 36, 963-973, https://doi.org/10.1109/36.673687.

Gallo, K., T. Smith, K. Jungbluth, and P. Schumacher, 2012: Hail swaths observed from satellite data and their relation to radar and surface-based observations: A case study from Iowa in 2009. Wea. Forecasting, 27, 796-802, https://doi.org/10.1175/ WAF-D-11-00118.1.

_ P. Schumacher, J. Boustead, and A. Ferguson, 2019: Validation of satellite observations of storm damage to cropland with digital photographs. Wea. Forecasting, 34, 435-446, https:// doi.org/10.1175/WAF-D-18-0059.1.

Haldar, D., A. Das, S. Mohan, O. Pal, R. S. Hooda, and M. Chakraborty, 2012: Assessment of L-band SAR data at different polarization combinations for crop and other landuse classification. Prog. Electromagn. Res. B, 36, 303-321, https:// doi.org/10.2528/PIERB11071106.

Hogenson, K., S. A. Arko, B. Buechler, R. Hogenson, J. Herrmann, and A. Geiger, 2016: Hybrid Pluggable Processing Pipeline (HyP3): A cloud-based infrastructure for generic processing of
SAR data. 2016 Fall Meeting, Washington, DC, Amer. Geophys. Union, Abstract G32A-03.

Hong, S. H., and S. Wdowinski, 2014: Double-bounce component in cross-polarimetric SAR from a new scattering target decomposition. IEEE Trans. Geosci. Remote Sens., 52, 30393051, https://doi.org/10.1109/TGRS.2013.2268853.

Howard, D. M., B. K. Wylie, and L. L. Tieszen, 2012: Crop classification modelling using remote sensing and environmental data in the Greater Platte River Basin, USA. Int. J. Remote Sens., 33, 6094-6108, https://doi.org/10.1080/01431161.2012.680617.

Ingram, T., 2018: Photo report of hail damage in Howard County. University of Nebraska-Lincoln CropWatch, accessed 9 April 2019, https:/cropwatch.unl.edu/2018/photo-report-hail-damagehoward-county.

Jiao, X., H. Mc Nairn, J. Shang, E. Pattey, J. Liu, and C. Champagne, 2011: The sensitivity of $R A D A R S A T-2$ polarimetric SAR data to corn and soybean leaf area index. Can. J. Rem. Sens., 37, 69-81, https://doi.org/10.5589/m11-023.

Johnson, B., C. Thompson, A. Giri, and S. V. NewKirk, 2011: Nebraska irrigation fact sheet. Department of Agricultural Economics Rep. 190, 6 pp., https://agecon.unl.edu/a9fcd9024da9-4c3f-9e04-c8b56a9b22c7.pdf.

Jones, B. P., D. L. Holshouser, M. M. Alley, J. K. F. Roygard, and C. M. Anderson-Cook, 2003: Double-crop soybean leaf area and yield responses to mid-Atlantic soils and cropping systems. Agron. J., 95, 436-445, https://doi.org/10.2134/agronj2003.0436.

Karjalainen, M., H. Kaartinen, and J. Hyyppa, 2008: Agricultural monitoring using Envisat alternating polarization SAR images. Photogramm. Eng. Remote Sensing, 74, 117-126, https:// doi.org/10.14358/PERS.74.1.117.

Kenduiywo, B. K., D. Bargiel, and U. Soergel, 2018: Crop-type mapping from a sequence of Sentinel 1 images. Int. J. Remote Sens., 39, 6383-6404, https://doi.org/10.1080/01431161.2018.1460503.

Klimowski, B. A., M. R. Hjelmfelt, M. J. Bunkers, D. Sedlacek, and L. R. Johnson, 1998: Hailstorm damage observed from the GOES-8 satellite: The 5-6 July 1996 Butte-Meade storm. Mon. Wea. Rev., 126, 831-834, https://doi.org/10.1175/15200493(1998)126\%3C0831:HDOFTG\%3E2.0.CO;2.

Kranz, W. L., and J. Specht, 2012: Irrigating soybean. University of Nebraska NebGuide-G1367, 4 pp., accessed 10 April 2019, http://extensionpublications.unl.edu/assets/pdf/g1367.pdf.

_ , S. Irmak, S. J. van Donk, C. D. Yonts, and D. L. Martin, 2008: Irrigation management for corn. University of Nebraska NebGuide-G1850, 4 pp., http://extensionpublications.unl.edu/ assets/pdf/g1850.pdf.

Kussul, N., M. Lavreniuk, S. Skakun, and A. Shelestov, 2017: Deep learning classification of land cover and crop types using remote sensing data. IEEE Geosci. Remote Sens. Lett., 14, 778-782, https://doi.org/10.1109/LGRS.2017.2681128.

Lakshmanan, V., T. Smith, G. J. Stumpf, and K. Hondl, 2007: The Warning Decision Support System-Integrated Information. Wea. Forecasting, 22, 596-612, https://doi.org/10.1175/WAF1009.1.

Larrañaga, A., and J. Álvarez-Mozos, 2016: On the added value of Quad-Pol data in a multi-temporal crop classification framework based on RADARSAT-2 imagery. Remote Sens., 8, 335, https://doi.org/10.3390/rs8040335.

Laur, H., P. Bally, P. Meadows, J. Sanchez, B. Schaettler, E. Lopinto, and D. Esteban, 2004: Derivation of the backscattering coefficient Sigma 0 in ESA ERS SAR PRI products. ESA Tech. Note ES-TN-RS-PM-HL09, 57 pp.

Li, J., and S. Wang, 2018: Using SAR-derived vegetation descriptors in a water cloud model to improve soil moisture retrieval. Remote Sens., 10, 1370, https://doi.org/10.3390/rs10091370. 
Liu, C., J. Shang, P. W. Vachon, and H. McNairn, 2013: Multiyear crop monitoring using polarimetric RADARSAT-2 data. IEEE Trans. Geosci. Remote Sens., 51, 2227-2240, https:// doi.org/10.1109/TGRS.2012.2208649.

Malinverni, E. S., D. T. Sandwell, A. N. Tassetti, and L. Cappelletti, 2014: InSAR decorrelation to assess and prevent volcanic risk. Eur. J. Remote Sens., 47, 537-556, https://doi.org/10.5721/ EuJRS20144730.

McNairn, H., C. Champagne, J. Shang, D. Holmstrom, and G. Reichert, 2009: Integration of optical and Synthetic Aperture Radar (SAR) imagery for delivering operational annual crop inventories. ISPRS J. Photogramm. Remote Sens., 64, 434-449, https://doi.org/10.1016/ j.isprsjprs.2008.07.006.

—- A. Kross, D. Lapen, R. Caves, and J. Shang, 2014: Early season monitoring of corn and soybeans with TerraSAR-X and RADARSAT-2. Int. J. Appl. Earth Obs. Geoinf., 28, 252259, https://doi.org/10.1016/j.jag.2013.12.015.

Molthan, A. L., J. E. Burks, K. M. McGrath, and F. J. LaFontaine, 2013: Multi-sensor examination of hail damage swaths for near real-time applications and assessment. J. Oper. Meteor., 1, 144-156, https://doi.org/10.15191/nwajom.2013.0113.

_ J. R. Bell, T. A. Cole, and J. E. Burks, 2014: Satellite-based identification of tornado damage tracks from the 27 April 2011 severe weather outbreak. J. Oper. Meteor., 2, 191-208, https:// doi.org/10.15191/nwajom.2014.0216.

Moreira, A., P. Prats-Iraola, M. Younis, G. Krieger, I. Hajnsek, and K. P. Papathanassiou, 2013: A tutorial on synthetic aperture radar. IEEE Geosci. Remote Sens. Mag., 1, 6-43, https://doi.org/ 10.1109/MGRS.2013.2248301.

Nagler, T., H. Rott, M. Hetzenecker, J. Wuite, and P. Potin, 2015: The Sentinel-1 mission: New opportunities for ice sheet observations. Remote Sens., 7, 9371-9389, https://doi.org/10.3390/ rs70709371.

National Agricultural Statistics Service, 2019: Published crop-specific data layer. CropScape - Cropland Data Layer, USDA, accessed 1 March 2019, https://nassgeodata.gmu.edu/CropScape/.

NCEI, 2019: Land-based station data. NOAA, accessed 10 April 2019, https://www.ncdc.noaa.gov/data-access/land-based-station-data.

Nguyen, D. B., A. Gruber, and W. Wagner, 2016: Mapping rice extent and cropping scheme in the Mekong Delta using Sentinel-1A data. Remote Sens. Lett., 7, 1209-1218, https:// doi.org/10.1080/2150704X.2016.1225172.

Ortega, K. L., T. M. Smith, K. L. Manross, K. A. Scharfenberg, A. Witt, A. G. Kolodziej, and J. J. Gourley, 2009: The severe hazards analysis and verification experiment. Bull. Amer. Meteor. Soc., 90, 1519-1530, https://doi.org/10.1175/2009BAMS2815.1.

Paloscia, S., G. Macelloni, P. Pampaloni, and S. Sigismondi, 1999: The potential of $\mathrm{C}$ - and L-band SAR in estimating vegetation biomass: The ERS-1 and JERS-1 experiments. IEEE Trans. Geosci. Remote Sens., 37, 2107-2110, https://doi.org/10.1109/ 36.774723 .

Parker, M. D., I. C. Ratcliffe, and G. M. Henebry, 2005: The July 2003 Dakota hailswaths: Creation, characteristics, and possible impacts. Mon. Wea. Rev., 133, 1241-1260, https://doi.org/ 10.1175/MWR2914.1.

Plank, S., 2014: Rapid damage assessment by means of multi-temporal SAR-A comprehensive review and outlook to Sentinel-1. Remote Sens., 6, 4870-4906, https://doi.org/10.3390/rs6064870.

Preiss, M., and N. J. S. Stacy, 2006: Coherent change detection: Theoretical description and experimental results. Defence Science and Technology Organisation Tech. Rep. DSTOTR-1851, 116 pp., https://apps.dtic.mil/dtic/tr/fulltext/u2/ a458753.pdf.
Rajah, P., J. Odindi, and O. Mutanga, 2018: Feature level image fusion of optical imagery and Synthetic Aperture Radar (SAR) for invasive alien plant species detection and mapping. Remote Sens. Appl. Soc. Environ., 10, 198-208, https://doi.org/ 10.1016/J.RSASE.2018.04.007.

Reigber, A., and Coauthors, 2013: Very-high-resolution airborne synthetic aperture radar imaging: Signal processing and applications. Proc. IEEE, 101, 759-783, https://doi.org/10.1109/ JPROC.2012.2220511.

Rouse, J. W., Jr., R. H. Haas, J. A. Schell, and D. W. Deering, 1974: Monitoring vegetation systems in the Great Plains with ERTS. Third ERTS Symp. Remote Sensing Center, College Station, Texas, Texas A\&M University, 309-317.

Sanyal, J., and X. X. Lu, 2004: Application of remote sensing in flood management with special reference to monsoon Asia: A review. Nat. Hazards, 33, 283-301, https://doi.org/10.1023/ B:NHAZ.0000037035.65105.95.

Scheuchl, B., T. Ullmann, and F. Koudogbo, 2009: Change detection using high resolution TerraSAR-X data preliminary results. Proc. ISPRS Hannover Workshop, Hannover, Germany, ISPRS, 5-10, http://www.isprs.org/proceedings/xxxviii/1_4_7-W5/paper/ Scheuchl-185.pdf.

Scott, C. P., R. B. Lohman, and T. E. Jordan, 2017: InSAR constraints on soil moisture evolution after the March 2015 extreme precipitation event in Chile. Sci. Rep., 7, 4903, https:// doi.org/10.1038/s41598-017-05123-4.

Shimada, M., 2010: Ortho-rectification and slope correction of SAR data using DEM and its accuracy evaluation. IEEE J. Sel. Top. Appl. Earth Obs. Remote Sens., 3, 657-671, https:// doi.org/10.1109/JSTARS.2010.2072984.

Small, D., 2011: Flattening gamma: Radiometric terrain correction for SAR imagery. IEEE Trans. Geosci. Remote Sens., 49, 3081-3093, https://doi.org/10.1109/TGRS.2011.2120616.

Song, Y., and J. Wang, 2019: Mapping winter wheat planting area and monitoring its phenology using Sentinel-1 backscatter time series. Remote Sens., 11, 449, https://doi.org/10.3390/rs11040449.

Stumpf, G. J., T. M. Smith, and J. Hocker, 2004: New hail diagnostic parameters derived by integrating multiple radars and multiple sensors. 22nd Conf. on Severe Local Storms, Hyannis, MA, Amer. Meteor. Soc., P7.8, https://ams.confex.com/ams/ pdfpapers/81451.pdf.

Torbick, N., X. Huang, B. Ziniti, D. Johnson, J. Masek, and M. Reba, 2018: Fusion of moderate resolution Earth observations for operational crop type mapping. Remote Sens., $\mathbf{1 0}$, 1058, https://doi.org/10.3390/rs10071058.

Tucker, C. J., 1979: Red and photographic infrared linear combinations for monitoring vegetation. Remote Sens. Environ., 8, 127-150, https://doi.org/10.1016/0034-4257(79)90013-0.

USGS, 2017: 3DEP products and services: The national map. 3D Elevation Program, accessed 10 January 2019, https:// nationalmap.gov/3DEP/3dep_prodserv.html.

Vermote, E., and R. Wolfe, 2015a: MOD09GQ-MODIS/Terra surface reflectance daily L2G global $250 \mathrm{~m}$ SIN grid V006. NASA EOSDIS Land Processes DAAC, 20 February 2019, https://doi.org/10.5067/MODIS/MOD09GQ.006.

$\longrightarrow$, and - 2015b: MYD09GQ MODIS/Aqua surface reflectance daily L2G global $250 \mathrm{~m}$ SIN grid V006. NASA EOSDIS Land Processes DAAC, accessed 20 February 2019, http:// doi.org/10.5067/MODIS/MYD09GQ.006.

, and $-2015 \mathrm{c}$ : MOD09GA MODIS/Terra surface reflectance daily L2G global $1 \mathrm{~km}$ and 500m SIN grid V006. NASA EOSDIS Land Processes DAAC, accessed 20 February 2019, http://doi.org/10.5067/MODIS/MOD09GA.006. 
— tance daily L2G global $1 \mathrm{~km}$ and $500 \mathrm{~m}$ SIN grid V006. NASA EOSDIS Land Processes DAAC, accessed 20 February 2019, http://doi.org/10.5067/MODIS/MYD09GA.006.

Viña, A., A. A. Gitelson, D. C. Rundquist, G. Keydan, B. Leavitt, and J. Schepers, 2004: Monitoring maize (Zea mays L.) phenology with remote sensing. Agron. J., 96, 1139-1147, https:// doi.org/10.2134/agronj2004.1139.

Wardlow, B. D., and S. L. Egbert, 2008: Large-area crop mapping using time-series MODIS $250 \mathrm{~m}$ NDVI data: An assessment for the U.S. central Great Plains. Remote Sens. Environ., 112, 1096-1116, https://doi.org/10.1016/j.rse.2007.07.019.

,-- , and J. H. Kastens, 2007: Analysis of time-series MODIS $250 \mathrm{~m}$ vegetation index data for crop classification in the US central Great Plains. Remote Sens. Environ., 108, 290-310, https://doi.org/10.1016/j.rse.2006.11.021.

Wegmuller, U., 1999: Automated terrain corrected SAR geocoding. Int. Geoscience and Remote Sensing Symp., Hamburg, Germany, IEEE, 1712-1714, https://doi.org/10.1109/ IGARSS.1999.772070.

Werner, C., U. Wegmüller, T. Strozzi, and A. Wiesmann, 2000: GAMMA SAR and interferometric processing software. Proc. ERS-ENVISAT Symp., Gothenburg, Sweden, ESA SP-461,
211-219, https://www.gamma-rs.ch/uploads/media/2000-1_ GAMMA_Software.pdf.

White, L., B. Brisco, M. Dabboor, A. Schmitt, and A. Pratt, 2015: A collection of SAR methodologies for monitoring wetlands. Remote Sens., 7, 7615-7645, https://doi.org/10.3390/ rs70607615.

Wiseman, G., H. McNairn, S. Homayouni, and J. Shang, 2014: $R A D A R S A T-2$ Polarimetric SAR response to crop biomass for agricultural production monitoring. IEEE J. Sel. Top. Appl. Earth Obs. Remote Sens., 7, 4461-4471, https://doi.org/10.1109/ JSTARS.2014.2322311.

Witt, A., M. D. Eilts, G. J. Stumpf, J. T. Johnson, E. D. Mitchell, and K. W. Thomas, 1998: An enhanced hail detection algorithm for the WSR-88D. Wea. Forecasting, 13, 286-303, https:// doi.org/10.1175/1520-0434(1998)013<0286: AEHDAF $>2.0 . \mathrm{CO} ; 2$.

Zhang, F., X. Zhu, and D. Liu, 2014: Blending MODIS and Landsat images for urban flood mapping. Int. J. Remote Sens., 35, 32373253, https://doi.org/10.1080/01431161.2014.903351.

Zhao, L., J. Yang, P. Li, L. Shi, and L. Zhang, 2017: Characterizing lodging damage in wheat and canola using RADARSAT-2 polarimetric SAR data. Remote Sens. Lett., 8, 667-675, https:// doi.org/10.1080/2150704X.2017.1312028. 